\title{
Compañías mercantiles sevillanas: capital social (siglos XVIII-XIX)
}

\author{
Jesús Jimeno Borrero ${ }^{1}$
}

Recibido: 30 de mayo de 2018 / Aceptado: 02 de julio de 2018

Resumen. El capital social de la compañía es un aspecto fundamental del contrato de sociedad. El presente artículo analiza mediante las cláusulas de las escrituras sociales, la legislación y la doctrina, la forma en la que se desarrolla durante un período histórico de especial importancia: la evolución desde la cultura jurídica del ius mercatorum hacia el régimen liberal y codificador del derecho mercantil. Esta investigación aborda aquellas cuestiones directamente ligadas al estudio del capital como su conceptualización y titularidad, su determinación exacta, los aumentos y las posibles detracciones. Además, otros temas que presentan conexidad al capital, como los fondos patrimoniales de los que dispone la sociedad, la relación entre capital y personalidad jurídica, y la responsabilidad del socio que no aporta bienes en el momento en que se constituye el capital.

Palabras clave: capital social; comercio; compañías mercantiles; sociedades; personalidad jurídica.

\section{[en] The trade companies in Seville: share capital $\left(18^{\text {th }}\right.$ and $19^{\text {th }}$ centuries $)$}

\begin{abstract}
The share capital of a company is a key element of a partnership contract. This paper analyzes the way in which the evolution of the Ius Mercatorum's legal culture towards the Liberal Regime and the Codifying of the Mercantile Law. This research has been carried out by means of analyzing clauses from deeds, law and doctrine. It is focused on subjects directly linked to the study of the share capital such as its exact determination, the increase and the possible reduction of it. As well as some other topics related to the share capital, as patrimonial funds available in the society, the relationship between the share capital and the legal entity, and the liability of the partner who do not invest assets in the memorandum of the association.
\end{abstract}

Keywords: share capital; trade; trade companies; commercial partnership; legal entity.

\section{[fr] Entreprises mercantiles sevillanes: capitale sociale $\left(\mathrm{XVIII}^{\mathrm{e}}-\mathrm{XIX}{ }^{\mathrm{e}}\right.$ siècles $)$}

Résumé. Le capital social de l'entreprise est un aspect fondamental du contrat de partenariat. Cet article analyse les clauses des actes sociaux, la législation et de la doctrine, ainsi que la façon dont il se développe sur une période historique d'une importance particulière: l'évolution de la culture juridique de ius mercatorum au régime libéral et dans la codification du droit mercantile. Cette recherche porte sur des questions directement liées à l'étude du capital en tant que conceptualisation et propriété, sa détermination exacte, ses augmentations et ses réductions éventuelles. En outre, d'autres questions ont connexité au capital, tels que les fonds d'actions à la disposition de la société, la relation entre le capital et la personnalité juridique, ainsi que la responsabilité du partenaire qui ne fournit pas des biens au moment où le capital est constitué.

Mots clé : capital social; commerce; compagnies mercantiles; societés; personnalité juridique.

Abogado y Doctor en Derecho con mención internacional por la Universidad Carlos III de Madrid

jimenoborrero@gmail.com 
Sumario: 1. Introducción. 2. El concepto y la titularidad del capital social. 3. La determinación del capital. aumento y disminución. 4. Otros fondos patrimoniales de la sociedad. 5. El momento de formación del capital social: el incumplimiento del socio. 6. Conclusiones. 7. Fuentes. 8. Bibliografía.

Cómo citar: J. Jimeno Borrero (2018). «Compañías mercantiles sevillanas: capital social (siglos XVIII-XIX)», Cuadernos de Historia del Derecho, XXV, 2018, 137-169.

\section{Introducción}

El presente artículo analiza el capital social de la compañía sevillana en los siglos XVIII y la primera mitad XIX. Un asunto, trabajado anteriormente en mi tesis doctoral sobre contratos societarios, cuyo interés requería de mayor desarrollo en un trabajo independiente.

El estudio del derecho de sociedades requiere la utilización de diferentes fuentes que permitan ahondar en el conocimiento de algunos aspectos del derecho de contratos y la forma en que se han desarrollado en un determinado momento histórico. Esta afirmación explica que, en el presente artículo, nos hayamos servido de una simbiosis contractual, legislativa y doctrinal, que facilite la comprensión del capital social en un período temporal determinado.

El capital social de la sociedad se entiende como uno de los requisitos fundamentales de la sociedad, ya que comprende la base patrimonial de la que dispone la compañía para hacer frente a los gastos, a las obligaciones contraídas y a la ejecución del giro de comercio para la que es constituida.

El estudio penetra en los elementos esenciales del capital social, no solo en su concepto y sus características esenciales, sino también, dimanante de la preocupación legislativa, doctrinal y casuística, aquellos supuestos que alteran la determinación exacta del caudal de la sociedad, su aumento o su disminución debido a una serie de circunstancias, generalmente pactadas en la escritura. Sin embargo, el patrimonio social no se ve circunscrito de forma estricta al acerbo común; la existencia de otros bienes ajenos al capital social permite una estabilidad económica y una capacidad negociadora necesarias para la continuidad de la sociedad. Por último, merece atención el momento efectivo de la conformación del capital, toda vez que supone una limitación a las posibles responsabilidades del patrimonio de la compañía frente a las deudas sociales o privativas.

\section{El concepto y la titularidad del capital social}

A pesar de tratarse de uno de los elementos nucleares de la sociedad mercantil, la doctrina de finales del siglo XVIII y del siglo XIX no se manifiesta especialmente preocupada por conceptualizar qué es el capital de una compañía, interesada, por el contrario, solo en aquellas características controvertidas con fines generalmente prácticos, como serían el monto exacto del capital o el momento en el que se constituye.

El capital debe entenderse como el conjunto de bienes de la sociedad sujeto a una valoración económica con la doble intención de, por una parte, servir al objeto de 
comercio y, por otra parte, asumir la responsabilidad patrimonial en la que pudiera incurrir la sociedad ante eventuales pérdidas ${ }^{2}$. La doctrina más autorizada, como por ejemplo Pardessus, así como los diferentes textos legales, coinciden en exigir la presencia, con independencia de la índole de los bienes que se entreguen, de una masa común formada por aportaciones de los socios de la compañía?

La exigencia legal de establecer en la escritura el capital social cuestiona la posible existencia de sociedades cuyo fondo está compuesto ab initio por la sola industria de los socios. Esta modalidad, conocida como sociedad opera cum opera propia de un arte u oficio ${ }^{4}$, presenta en los contratos sevillanos - en la línea de los resultados obtenidos por el profesor Carlos Petit sobre la práctica bilbaína - un carácter residuals. Sin embargo, encontramos escrituras que se le aproximan, como sucede con De la Fuente / Vidal, donde ambos socios constituyen compañía para la recolección de granos y de las semillas tras la obtención de licencia de la Mesa Capitular del Cabildo, sin que pueda apreciarse la existencia de capital alguno, salvo la propia industria de ambos socios ${ }^{6}$. Otro supuesto próximo se produce en Vicedo / Calero / Ca-

En este sentido se expresan Martínez Gijón, Historia del derecho mercantil, Sevilla, Universidad de Sevilla, 1999, pp. 434-435, y Carlos Petit, La compañia mercantil bajo las ordenanzas del Consulado de Bilbao 17371829, Sevilla, Universidad de Sevilla, 1980, p. 111.

3 J. M. Pardessus fundamenta en la obligatoria aportación del socio la esencia misma de la sociedad mercantil, deslindándola de la donación de una porción de intereses que pudiera realizar un socio, que, aún no estando prohibida, estaría sujeta a las reglas del derecho civil. En la misma línea se expresa el autor francés sobre la posibilidad de que un socio pudiera retirar la aportación cuando lo creyese oportuno, en cuyo caso se trataría de la existencia, no de un contrato de sociedad, sino de un préstamo, aunque hubiera adoptado la fórmula societaria; Cours de droit commerce, tomo II, sexta edición, Augmentée de la Législation et de la Jurisprudence Belges, Bruxelles, Librairie de Jurisprudence de H. Tarliere, 1836, núm. 983, pp. 484. Los dos textos de vocación normativa y origen sevillano exigen recoger en la escritura el capital aportado por los socios, ya sea en «cantidad de dinero» o «en efectos», como testimonia el proyecto de Ordenanzas de Nuestra Señora de la Inmaculada (cap. $\mathrm{v}$, ley 2): «En ella [la escritura] se insertarán los Poderes en virtud de que alguno se incluya en ella el tpô en que ha de empezar y fenecer la cantidad en dinero o efectos que cada uno pusiese por capital, â los que se ha de dar su valor») y el proyecto de Ordenanzas del Consulado Nuevo de Sevilla (ley 40: «[obliga a escriturar] por ante Escribano, con expresión de los socios, fondos, y parte de cada uno»). El texto de Málaga repite la misma fórmula (art. 468: «La escritura debe expresar: [...] El capital que cada uno introduce en dinero, efectos y créditos con referencia precisa o inventario. La parte que en beneficios y perdidas corresponda a cada socio capitalista, y la del industrial si lo hubiere»). Finalmente, el Código de 1829 establece en el art. 286 que «La escritura debe espresar necesariamente: Los nombres, apellidos y domicilio de los otorgantes. La razón social ó denominación de la compañía. Los socios que han de tener á su cargo la administración de la compañía, y usar de su firma. El capital que cada socio introduce en dinero efectivo, credito ó efectos; con espresion del valor que se dé á estos, ó de las bases sobre que ha de hacerse el avalúo. La parte que haya de corresponder en beneficios y pérdidas á cada socio capitalista y á los de industria, si los hubiere de esta especie [...]», coincidiendo con el Code (art. 43: «L'extrait doit contenir. [...] Le montant des valeurs fournies ou á fournir par actions ou en commandite»).

J. Martínez Gijón, Historia del derecho mercantil, p. 435.

Carlos Petit, La compañia mercantil, p. 111. Diferente es el caso del Cádiz de la segunda mitad del siglo XVII, María Guadalupe Carrasco González, Los instrumentos del comercio colonial en el Cádiz del siglo XVII (16501700), Banco de España-Estudios de Historia Económica, n 35, 1996, pp. 29-36, donde el 43\% de los contratos examinados no establecen ninguna referencia al capital social de la compañía y solo el $40 \%$ de las escrituras recogen la cuantía que ha de entregarse al fondo común, pudiendo concluirse la existencia de un elevado número de compañías constituidas en base al trabajo de los socios.

6 De la Fuente / Vidal, AHPS, legajo 2884, fol. 655, Sevilla, 1769: «Y dezimos que por quanto por los señores de la Mesa Capitular del Cavildo de las Yglesia de esta ciudad, sera rematado como mayores postores de mancomun e Yssolidum las rentas, de Pan de las Parrochialas de esta Maria Mag., San Julian, y San Vicente de esta Ciudad, juntamente con las semillas de esta ultima mediante lo cual y para que en razon de la recoleccion de los granos y semillas, y Maravedies que por causa de otras rentas se guarde la devida formalidad, que como compañeros no se nos siga en ello disgusto en enemistad ni otro genero de discordia estamos de comun acuerdo 
rrasco / Lerrezuelo / Merlo porque, aún aportando cada uno de los asociados caballos o carruajes, éstos han de entenderse en el sentido de opera más que en relación con el valor de lo entregado en concepto de un género. La ausencia de valoración del bien entregado (caballo y coche) permiten considerar la sociedad de opera cum opera .

Junto a este tipo asociativo, que, en un sentido estricto, encomienda el fondo común a las labores de los compañeros, encontramos otros contratos en los que el capital no se delimita en el momento constitutivo de la sociedad, sino que el socio capitalista se compromete a la aportación de sucesivas cantidades pecuniarias cuando fueran necesarias para el sostenimiento de la actividad mercantil. Son los casos de una de las escasas sociedades con un letrado como socio: José María Tirado, quien la pacta para la tala de alcornoques mediante subasta realizada por las «Justicias de la Villa de Almaden de la Plata ${ }^{8}$. Otro supuesto similar se observa en Mariano

y conformidad en sugetarnos como con efecto nos sugetamos para ello a los Capitulos siguientes: Primeramente en prevencion q. los rendimientos que se despacharen pasen el preciso de los efectos de dichas rentas an de ser amo y Caveza de mi el otro D Joseph de la Fuente sin que contra ello yo el dicho Juan Antonio Vidal pueda hir sin venir en manera alguna. Que despachado los otros rendimientos amvos compañeros juntos y no el uno sin el otro hemos de recivir los otros efectos de Granos, Semillas, y maravedies y an de entrar en Poder de mi el otro D. Joseph de la Fuente para su deposito Yntexion y Hasta tanto se satisfaren los libramientos que contra nosotros fueren despachados y enteramente concluyemos compañía entre los dos lo q. de ello quedare sin que en contra de ello podamos hir ni venir en manera alguna. Que con la misma Intevencion de amvos se an de pagar los libramientos que contra nosotros fueron despachados hasta enteramente satisfaren las obligaciones q. por estas rentas cubriremos sin contradicion alguna».

7 Vicedo / Calero / Carrasco / Lerrezuelo / Merlo, AHPS, legajo 1976, fol. 334, Sevilla, 1835: «Que teniendo el primero una Calesa y un Carro, el Segundo una Calesa, el Tercero un Carro, el quarto una Calesa, y el quinto una Calesa, con cuyos Carruajes portean las Arrobas y Bagajes que se le proporcionan desde esta Ciudad hasta la Villa y Corte de Madrid, su carrera y ciudad de Cadiz, y queriendo no causarse perjuicio unos a otros, han determinado sentar compañía que establecen y sienten compañía en dichos Carruajes para transportar arrobas y bagajes desde la Villa y Corte de Madrid a esta Ciudad de Sevilla y su Carrera y Ciudad de Cádiz respectiva digo por tiempo de un año que empezará contarse en el día veinte del presente mes de Mayo de esta fecha, y cumpliran igual día y mes de el que viene de mil ochocientos treinta y seis; durante cuyo tiempo hemos de trabajar todos igualmente con nuestros respectivos Carruajes sin falta ni excusa alguna, haciendo todas las conclusiones y Portes que se ofrezcan tanto a unos como a otros. La primera que todas las arrobas que se conduzcan por todos o cualesquiera de los cinco compañeros desde esta ciudad a cualesquiera de los puntos detallados en esta Escriptura, o desde aquellos a esta Ciudad y su Carrera han de ser puesto a un precio a el tiempo que se reparta su producto entre todos en cada liquidación, pues aunque sean de mas o menos se han de nibelar para que todos cinco compañeros percivan igual interes el que se habrá de repartir en la Villa y Corte de Madrid o en la Ciudad de Cádiz precisamente en cada viaje, perciviendo cada uno de los cinco interesados la cantidad respectiva a lo que haya porteado con su Carruaje, sin poder exigir mas cuota ni compensación, a todo lo que se les ha de poder recombenir respectivamente en forma legal. La segunda que si se necesitaren mas Carruaje que los que al presente tienen todos los cinco Compañeros por haver mas cargamento que el que estos puedan portear se han de buscar otros por cualesquiera de los cinco compañeros que lo necesiten abonando entre todos el alquiler o cuota, en que se ajusten como también se habrá de repartir entre los mismos lo que produzcan tambien en cada viaje y en los puntos que han designados para la repartición y liquidación de cuentas. La tercera que si se verificare que alguno o algunos de los cinco compañeros en esta aparceria cometiere algun fraude porque quiera abonar o abone los portes que haya echo a menos precio que lo que haya afastado, o no entregare el importe que haya producido cada viaje, por este hecho ha de quedar como desde luego quedan excluidos de todo el derecho y accion que tengan a percibir la parte de interes que por aquel viaje le corresponda sin perjuicio de quedarle la accion espedita a los demas compañeros para pedir judicialmente contra el que haya delinquido los daños y perjuicios que se le hayan inferido y las costas que para hacerle cumplir se causen».

$8 \quad$ Sevilla / Thirado, AHPS, legajo 3824, fol. 287-289, Sevilla, 1807: «Josef Ma Thirado Abogado de los Reales Consejos vecino y del Colegio desta Ciudad y Vizente de Sevilla vecino de Arazena en la Poblacion de Puerto Moral residente en esta Ciudad y Dixeron que haviendose rematado a favor del ultimo en publica subasta por las Justicias de la Villa del Almaden de la Plata en el año pasado [...] la corta de mil quinientos quarenta Alcornoques de cierto diametro en el sitio que llaman el Berrocal y obteniendose para ello la aprobacion de dicha 
García y Compañía, donde uno de los compañeros entrega de su «propio caudal» el «dinero» que requiera el socio industrial`. Por último, Colomés y Compañía presenta particularidades próximas, porque el socio capitalista proporciona las sumas necesarias para el manejo de la sociedad mientras que el socio industrial aporta los enseres requeridos para iniciar la actividad comercial ${ }^{10}$.

La casuística sevillana parte de la común y general determinación del capital social, aunque se exceptúen algunas sociedades mercantiles en las que el fondo queda indeterminado a la formalización del contrato, como en la sociedad Alonso / Ximénez, donde el caudal procede, en primer lugar, de la liquidación de una compañía contratada previamente de forma verbal y, en segundo lugar, de las aportaciones que proceden de uno de los socios ${ }^{11}$. Más llamativo resulta el caso de la compañía Lefabre / Lugar de Andrade, en la que el compañero Francisco Lefabre aporta el ingenio

Subasta, y lizencias nesesarias procedio a la referida Corta haviendo celebrado cierto contrato de Compañía con el D. Josef Thirado, obligandose este a concurrir con los desembolsos que fuesen nesesarios para la operación y el Sevilla poner de su parte la industria y trabajo personal perciviendo por esta razon dos partes de cinco de utilidades y las tres restantes el D. Josef Maria mas haviendose mandando suspender la Corta de dichos Arboles [...]. Primeramente es condicion desta Compañía que el D. Josef Maria Thirado ha de ser y queda obligado á concurrir con todas las cantidades que sean necesarias asi para la Corta de Arboles como para las dilixencias Judiciales q se estan practicando y fuese presiso practicar en adelante. 2a . Que el Vizente de Sevilla ha de poner en parte su industria y personal trabajo, percibiendo cada uno la mitad de utilidades que produzca la negociacion, ó satisfaciendo igualmente por mitad qualesquiera perdida que nasca de la misma deviendo perciva el Sevilla ademas de la mitad de utilidades la cantidad de doscientos reales vellon».

9 D. Mariano García y Compañía, AHPS, legajo 2909, fol. 747-750, Sevilla, 1793: «Que yo dicho Don Juan é de continuar como hasta áqui dando y entregado de mi proprio caudal á otro D. Mariano todo el dinero que nesesite para dicha compañía dándome su correspondiente recivo de ellas para firmarle el cargo cada, y quando liquidemos incluyendo en el ciento dos mill setecientos quarenta, y seis reales vellón que hasta fin de Agosto pasado de este año le tengo entregado $\mathrm{p}^{\mathrm{a}}$ el mismo efecto del tiempo anterior, $\mathrm{y}$ lo acreditan sus recivos que tengo en mi Poder aun que de ellos me á manifestado su distribución: en cuyo papel ú otro separado á de continuar firmando los tales recivos de las partidas que yo le vaya entregando [...]. Que dicho Don Mariano é de poner solo en esta compañía á mi intelexencia, cuidado, y manejo de dicha lavor siendo de mi cargo solicitar los cortijos, y tierras que acomoden tomandolos en arrendamiento de sus propietarios por los tiempo precios formas de pagar, y condiciones que estipulare solemnisando á mi nombre [...]».

10 Colomés y Compañía, AHPS, legajo 2974, fol. 54-57, Sevilla, 1845: «Primera. El Colomés como socio capitalista aportará á la Compañía todo el dinero que para su manejo sea necesario: y el Nuñez como industrial lo hará de diez telares armados con sus correspondientes avios de tornos, aviaduras, lanzaderas y demas herramientas. Tercera. La casa donde la Fábrica se establezca ha de ser habitada por el Colomés y por consecuencia no solamente satisfará este la parte de su renta que á prorrata con la dependencia le corresponda [...], sino que también será responsable de todos los géneros».

11 Alonso / Ximénez, AHPS, legajo 1345, fol. 294, Sevilla, 1757: «Que desde el mes de Julio próximo pasado de mil setescientos, cincuenta y seis antenido Compañía por Contrato Verbal en el trafico de todas redes para pesqueria de Labada, y Bandurría en el Rio de esta Ciudad con su barco y demas peltrechos correspondientes para su uso en todo lo cual tiene cada uno la mitad de su valor, y ha sido dicha Compañía a perdidas o ganancias por mitad igualmente por quanto el referido Manuel Ximénez ha corrido con el expresado tráfico, y el enunciado Juan Alonso suplido de su propio Caudal todos los costos y para el han sido precisos, y en la propia conformidad estan de acuerdo aya de venir, y siga la otra compañía desde hoy en adelante por el tiempo que fuere voluntad de ambos otorgantes sin señalar termino alguno, porque si cualquier de los dos quisiere separarse de ella lo ha de poder hazer siempre que le parezca, y respecto a que el trafico de la referida Compañía queda y está a cargo y cuidado del nominado Manuel Ximénez como inteligente en él se obliga a dar la quenta al referido Juan Alonso, cada y cuando que durante la Compañía, y cuando se tenera se la pidiere, y pagarle la cantidad o cantidades que en contra el resultaren en que fuere alcanzado en esta Ciudad llanamente sin pleito alguno luego que concrete sin aguardar mas termino, ni plazo con las cosas de su cobranza porque conveniente se le pueda Executar en virtud de esta Escritura y el pedimento jurado del referido Juan Alonso, o de quien su poder o causa huviere sin mas prueba, ni otra diligencia alguna aun que otro se requeria de que le releva. Y por quanto de las quentas que an efectuado del tiempo que hasta este día antenido de la otra Compañía que aprueban ratifican por averse liquidado a satisfacción de ambos otorgantes». 
para el refino de azúcar según privilegio obtenido por Real Cédula, mientras que el consocio formula la promesa de buscar enseres y accionistas que hagan factible el sostenimiento y el aprovisionamiento de la fábrica ${ }^{12}$.

Por último, los documentos consultados reconocen la existencia de otra sociedad de capital indeterminado, como es el caso de la cancelación de Morales / Murube, donde Alonso Morales se compromete a ser fiador solidario del contrato de arrendamiento de tierras que origina la constitución de la compañía ${ }^{13}$.

Otra cuestión que debe analizarse es la relacionada con la titularidad de los bienes aportados en concepto de capital social y con el poder de disposición tras la liquidación de la sociedad. En idénticos términos a los empleados respecto al concepto de capital social, hemos de pronunciarnos sobre el silencio de la doctrina y de la propia

12 Lefabre / Lugar de Andrade, AHPS, legajo 2904, fol. 826-831, Sevilla, 1788: «Que el dicho D. Francisco Lefabre octube Real Cedula de Su Magestad en la que se me concedio la direccion de fabrica de refinar de asucares en todo el Reyno donde y como tuviere por conveniente por termino de diez años primeros siguientes contados desde que por mi representasen á su M. las primeras muestras de Asucares Refinados [...], que é principiado á construir en esta Ciudad, y por quanto hallándome con nesesidad vigente de hacer A su ciencia de ella para pasar assi al Reyno de Francia como á otras partes á distintos asuntos que me inpiden la continuacion de dicho manejo asi por este motivo como es indispensable de tomar en calidad de las personas cavildos, comunidades, y de quienes les encontrase para el total establecimiento de dicha fabrica, causa por que se me dilatara Asunptos, para el Remedio de todo, me é comvenido con el explicado Don Domingo Lugar de Andrade en Cederle como le cedo, Renuncio y traspaso el citado privilegio, y demás Reales Cedulas que á su Consequencia é ganado ásta áqui que por el dicho tiempo de diez años contados desde que á si se presenten á su magestad dichas prímeras muestras de Asucares de dicha fabrica en adelante, y todo el tiempo que ádemas se le prorrogare siga con la direccion, manejo, Administracion, y disposición de dicha fabrica con todas las facultades, excepciones, prerrogativas, Privilegios $[\ldots]$ y el susodicho adquiriere, ganare de nuevo solicitando su entera conservación y manutención defendiendo su estabilidad firmeza, y cumplimiento judicial, y extrajudicialmente cada y quando que se ofresca usando de las facultades de tal único director sin mi intervención ni la de otra ninguna persona por que por ningún caso la á de tener ni yo con pretexto alguno la é de intentar mas que en los casos que ádelante serán manifestados: y en esta intelixencia á de usar con dichos Reales Privilegios y Cedulas de todas las facultades de tal director de dicha fabrica donde y como tenga por conveniente en los dominios de España, para lo que le pongo, y subrrogo en mi propio lguar grado y derecho para que le represente con general Administracion. Que yo dicho explicado Don Domingo Lugar de Andrade me obligo á consecuencia del citado Real Privilexio a buscar y facilitar para el fomento Conservacion, y augmento de dicha Fabrica de Refinar Asucares, y sobre todos los efectos utensilios, y Enseres de ella de treinta á quarenta Millones de Reales dentro de tres meses contados desde el dia que se presenten á Su Magestad las citadas primeras muestras de ásucares Refinadas en la citada fabrica que se éstá estableciendo en esta ciudad bajo de la direccion, y Administracion de mi dicho Don Francisco Lefebre. Cuya Cantidad á de entrar en Poder del caxero que sea de la satisfacción de los accionistas que dén dicho dinero para que en fuerza de mis libramientos como tal director, y con su aprecio de su inversión para dicha fabrica y no para otro efecto álguno, me vaya entregando las partidas, que se necesitaren».

13 Cancelación de la compañía Morales / Morube, AHPS, legajo 2893, fol. 305, Sevilla, 1778: «Alonso Morales, que por mi particular, y como marido, y con junta persona que soy de $\mathrm{D}^{\mathrm{a}}$ Antonia de Ayala, de otra persona: Desimos que con el motivo de haver continuado la dicha Doña Antonia por muerte de su primer marido D. Bartolome Brase, en el arrendamiento de la hazada de olivares, tierras y demas q en dicha Villa de Salteras pertenece a los mayorazgos que posehee el Excmo. Sr. Marques de Castro Monte, Conde de Villa Hermoso, y Cantillana, a cuya seguridad y pago de su Renta yo el citado D. Santiago me constituyo su fiador en la escriptura q para ello se otorgó ante el presente Escribano en el año pasado de mil setescientos setenta y seis, con cuyo motivo dicha $\mathrm{D}^{\mathrm{a}}$. Antonia, y yo el citado D. Santiago acordamos cierta compañía de manejo, fruto, y utilidades de dicha hazada, en la que seguimos hasta que en el año proximo pasado cesó el efecto, y manejo de dicha hazada, por no haver aprobado su Excelentísima el citado arrendamiento. En fuerza de lo qual, y á tenor concluídos todos los assumptos y Quentas de dicha Compañía: otorgamos q la distratamos, y nos separamos de ella, y por consiguiente como satisfechos q nos confesamos de ntrôs respectivos yntereses chancelamos y damos por ninguno y de ningun valor, ni efecto los contratos de dicha compañía q tengamos, echos y otorgados, $\mathrm{p}^{\mathrm{a}} \mathrm{q}$ ningunos valgan ni hagan fe y por libre y á ntrôs vienes de su responsabilidad $\mathrm{p}^{\mathrm{a}}$ prê, y consentimos q la razon de este distrato, y chancelacion, se prevenga y anote en el registro de dichas escripturas». 
legislación sobre este punto. Para una mayor comprensión del capital social, debemos atender a la división realizada por Carlos Petit en su estudio de las compañías

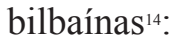

- la pertenencia del capital a la sociedad.

- la sociedad opera como una comunidad. El capital pertenece a los socios, en quienes concurre esta condición y la de copartícipes de los bienes adscritos al fondo de la compañía.

- los socios capitalistas se reservan para sí el derecho de propiedad sobre la cosa aportada al acerbo común.

La primera posibilidad cobra escasa significación desde una perspectiva práctica en los contratos analizados. Sin embargo, la historiografía y la dogmática focalizan esta cuestión societaria desde diferentes aspectos: primero, en los tiempos previos a la codificación, por su inclusión forzosa en la conocida societas totorum vel omnium bonorum, donde se comunican las ganancias obtenidas por la sociedad y cualquier otra de los socios ${ }^{15}$. Y segunda, por su conexidad con la interpretación de la sociedad como una persona jurídica.

La importancia de historiográfica de la personalidad jurídica a partir de la legislación codificada de los inicios del siglo XIX requiere de una específica atención. Federico de Castro niega la personalidad jurídica de la sociedad desde el derecho romano, ya que aquélla creaba una simple relación obligatoria dependiente de la voluntad de los socios y porque las aportaciones de los socios, aunque presenten cierto carácter unitario, no se conciben de forma separada de cada socio ${ }^{16}$. Para Tulio Ascarelli, la expansión económica colonial y el origen de las sociedades por acciones ocasiona la confluencia de formas asociativas económicas con el concepto de personalidad jurídica, procedente de la concesión expresa del monarca de privilegios a compañías de naturaleza que no pueden calificarse, en sentido estricto, de privadas ${ }^{17}$.

La doctrina emanada tras la publicación del Code de Commerce francés y el Código de Comercio de 1829 atribuyen la personalidad jurídica a la sociedad, bajo el término «ser moral». Una idea formulada a través del artículo 539 del Code Civil que no atribuye la propiedad de los bienes de la compañía a los socios proindiviso, sino a la propia sociedad, reconociendo la autonomía patrimonial de esta última, al menos, en cuanto a su activo ${ }^{18}$. El comentarista más importante del Code, J. M. Pardessus

14 Carlos Petit, La compañia mercantil, pp. 112-116.

15 Este tipo asociativo ya se recoge en las Partidas, 5, 10, 3: «[...] que todas las cosas que han quando fazen la compañía, e las que ganaren dende adelante, sean comunales, e también la ganancia, como la perdida, que pertenesca a todos». En este sentido, Martínez Gijón, Historia del derecho mercantil, pp. 422-423. Por otra parte, María Guadalupe Carrasco González, Los instrumentos del comercio colonial, pp. 29-36, halla una compañía universal en la que se refleja la pervivencia del derecho castellano en la práctica societaria, comunicándose todas las ganancias que obtengan los compañeros.

16 Federico de Castro, La persona jurídica, pp. 22-23.

17 Tulio Ascarelli, Iniciación al estudio del derecho mercantil, Bosch, Barcelona, 1964, p. 55. Sobre esta cuestión también se refieren diferentes autores; Jesús Rubio, Sainz de Andino y la codificación mercantil, pp. 153-160; Carlos Petit, La compañia mercantil, pp. 60-61, y recientemente en Historia del derecho mercantil, pp. 172-194, e Isidoro Antonio Calvo Vidal, La persona jurídica societaria, Madrid, Consejo General del Notariado, 2011, p. $58-62$.

18 Sobre la relación entre la personalidad jurídica de la sociedad y el art. 539 del Code Civil; Jean Foyer, «Sens et 
refiere la nueva concepción de la compañía de comercio, cuyos efectos se ramifican en todas las etapas de la vida social, con extraordinario interés en materia de la responsabilidad de los socios y del capital social ${ }^{19}$. La doctrina española reproduce, generalmente, las tesis sostenidas por el autor francés. En este sentido, Martí de Eixalá adjudica a la nueva sociedad del Código de Comercio dos efectos generales: de una parte, la producción de derechos y obligaciones entre los sujetos que constituyen el contrato, y de otra, del contrato de sociedad mercantil, se origina una nueva persona jurídica, un «nuevo ser comerciante» ${ }^{20}$. González Huebra considera que cuando las sociedades se constituyen con las formalidades prevenidas, las sociedades producen obligaciones entre los socios que la forman, pero además esta asociación establece una persona jurídica distinta de los individuos que la componen, un nuevo comerciante con los mismos derechos y obligaciones que cualquier otro, con la capacidad legal necesaria para contratar, no solo con extraños, sino también con los individuos de que estaba compuesta ${ }^{21}$.

Mayor interés desde un punto de vista casuístico presentan los dos restantes supuestos, mayoritarios en las escrituras analizadas. Las opciones obedecen a la posible modulación de dos diferentes aspectos: de una parte, la voluntad de los socios plasmada en el documento notarial determina, si el capital ha sido conferido en concepto de uso o propiedad, así como el grado de disponibilidad que se haya reservado el socio aportante; de otra parte, la naturaleza de los bienes aportados ${ }^{22}$.

La reserva del bien entregado en concepto de capital social goza de primacía en la práctica sevillana, aunque algunas escrituras de compañías optan por comunicar los fondos comunes, dividiéndose entre los socios las ganancias y el capital social tras la liquidación de la sociedad, detrayendo las cantidades abogadas en concepto de gastos. Esta naturaleza asociativa hunde sus raíces en el axioma latino non est societas sine communione, y se justifica en las sociedades sevillanas por el valor similar de los bienes aportados y por la naturaleza de los mismos. Mientras que la desigualdad

portée de la personnalité morale des sociétés en droit francais», en S. Bastid; R. David; U. Drobnig; L. Focsaneanu; J. Foyer; J. Grossen, La personnalité morale et ses limites. Études de droit comparé et de droit international public, Libraire Générale de Droit et de Jurisprudence, París, 1960, pp. 115-116, y Ugo Petronio, «Un diritto nuovo con materiale antichi: il Code de commerce fra tradizione e innovazione», en Negozianti y imprenditori, 200 anni dal Code de commerce, Milán, Mondadori-Sapienza Universitá di Roma, 2008, pp. 1-45. Algunas voces doctrinales atribuyen a la codificación este hallazgo técnico jurídico, aunque, en muchas ocasiones, sin fundamentar ni explicitar adecuadamente las circunstancias históricas de la legislación revolucionaria y su correlativo eco en el derecho mercantil español; Arturo García Sanz, «Las sociedades mercantiles en el Código de Comercio de 1829», en Miguel Ángel Chamocho Cantudo, Jorge Lozano Miralles (ed.), Sobre un hito jurídico de la constitución de 1812, Jaén, Universidad de Jaén, 2012, pp. 823-838, y Rafael Ansón Peironcely, La ley y el reglamento de 1848 sobre compañias mercantiles por acciones, Tesis doctoral dirigida por Juan Sánchez-Calero Guilarte, Madrid, Universidad Complutense, 2015, pp. 48-50 y 63-65.

19 Sobre la personalidad jurídica en la concepción societaria de J. M. Pardessus, Cours de droit commercial, núm. 975, pp. 479-480. En este sentido, Laura Moscati, «Pardessus e Il Code de Commerce», en Le matrici del diritto commerciale tra storia e tendenze, a cura di Serenella Rossi y Claudia Storti, Bari, Insubria Universtity Press, 2009, pp. 39-53.

20 Martí de Eixalá, Instituciones de derecho mercantil, pp. 257-258.

21 Pablo González Huebra, Curso de Derecho Mercantil, Madrid, Librería de Sanchez, 1867, pp. 119-120.

22 La naturaleza de los bienes aportados como elemento decisorio para la devolución a cada socio tras la posterior liquidación es una cuestión referida por diferentes autores, citamos principalmente a J. M. Pardessus, Cours de droit commerce, núm. 984, pp. 484-485, y a Alejandro de Bacardí, Tratado de Derecho Mercantil de España, Barcelona, Imprenta de D. Benito Espona, 1840, pp. 223-226, reproduce las palabras del jurista francés. 
de las aportaciones realizadas por los compañeros, explica la reserva de la propiedad de los bienes entregados al caudal común ${ }^{23}$. La proporcionalidad entre las aportaciones se observa en el caso de la compañía Colarte / Díaz, en la que ante la suma aportada por el socio capitalista, Antonio Colarte, el otro obliga su comercio de aguardientes, por lo que resulta coherente la comunidad sobre las futuras ganancias y capitales ${ }^{24}$. A la proporcionalidad de los fondos entregados por los socios también han de unirse otros factores, como sería la naturaleza de la propia actividad y del propio bien; así, en la compañía de los súbditos franceses Ponti / Piana, cuyo objeto consiste en la explotación de la fonda «El León de Oro ${ }^{25}$. Finalmente, una de las escasas sociedades anónimas encontradas no se

23 Ricardo Franch Benavent, Crecimiento económico y enriquecimiento burgués en la Valencia del siglo XVIII, Alfons el Magnanim, Valencia, 1986, pp. 251-256, reconoce en la práctica societaria valenciana una muy variada aportación cuantitativa y cualitativa en la que solo seis contratos de los cincuenta y dos examinados acuerdan una cantidad similar. Sin embargo, debe prestarse especial atención al valor fundamental de los saberes mercantiles como una caracterización societaria del período comprendido y un elemento valorable en el caudal de la compañía que permite la introducción de los factores y de los familiares en los negocios jurídicos y la correspondiente igualación de las ganancias futuras. Sobre esta cuestión, Carlos Petit, Historia del derecho mercantil, Madrid, Marcial Pons, 2017, pp. 73-74. Para el comercio americano, Arrigo Amadori / Josué Caamaño Dones, «Los «factores mercantiles» en el comercio indiano a través de la legislación y la literatura jurídica (siglos XVI-XVIII)», en Revista Complutense de Historia de América, (2006), vol. 32, pp. 85-101. Por último, Alberto García Ulecia, «Las condiciones de licitud de la compañía mercantil en Castilla bajo el derecho común», en Historia, Instituciones, Documentos, 7, (1980), pp. 39-94, establece la aequalitas que debe guardarse entre los derechos y las obligaciones de los compañeros, como uno de los límites a la omnívora libertad de pactos, aunque este hecho no supone la necesaria igualdad de las cuantías económicas entregables al fondo común.

24 Colarte / Díaz, AHPS, legajo 2893, fol. 856, Sevilla, 1778: «Y decimos que por quanto hallandome yo el dicho Pedro Diaz de la Cruz con el trafico y fabrica de Aguardientes y Vinos en dicha Villa y necesitando de algunos reales $\mathrm{p}^{\mathrm{a}}$ emplear en el mismo trafico, el explicado Don Antonio Colarte me á facilitado $\mathrm{p}^{\mathrm{a}}$ dicho efecto seis mill reales vellon los que me entrega áora la presente realmente y con efecto en especie de oro, y moneda redonda de cordoncillo lo mas de ella moneda gruessa ante el presente Escribano Publico. Para con dicha cantidad yo el citado D. Antonio por prê = Y dicho Pedro Diaz trabajo é yndustria estableser, como en efectos establesemos, y hacemos compañía por el tpô de la voluntad de cada uno de nos como no pase de tres años q empiesan a correr y contarse desde oy de la fecha en cuyo yntermedio cada y quando lo tengamos por conveniente nos podremos por separar libremente avisandonos $\mathrm{p}^{\mathrm{a}}$ ello el tpô antecedente $\mathrm{q}$ sea regular assi $\mathrm{p}^{\mathrm{a}}$ el ajuste de quenta y conclusion, de los asumptos pendientes como para facilitar para cada qual sus yntereses q le correspondan: Cuya compañía la é de manejar, administrar, y seguir yo el citado Pedro Diaz por mi sola direccion, assi en dicho trafico de vinos, y Aguardientes como en los demas drôx y efectos que tenga por conveniente assi en dicha villa como fuera de ella, pero con la precisa obligacion de aver de dar quenta al citado D. Antonio de los proeiectos y empleos q se ofrezcan haser antes de principiarlos, $\mathrm{p}^{\mathrm{a}} \mathrm{q}$ lo execute por quenta de ambos, Sprê que dicho Don Antonio no tenga reparo y condescienda en ello; pues de lo contrario seria de mi cargo el quebranto y menos Cabo que abiere: Y concluido qualquier empleo que se hiciere, y vendido sus efectos, yo el referido Pedro Diaz quedo obligado a dar quenta con pago D. Antonio en esta Ciudad entregandole la mitad del liquido de las ganancias que habiere de dichos empleos, despues de rebajados los gastos é ympendios q en ellos se ofreciere, y en esta conformidad sea de seguir la explicada compañía hasta cumplirse al termino de los tres años antes cada y quando nos quisieremos separar de ella: En cuyo casso dada la quenta final del ultimo empleo yo el citado Pedro Diaz le e de entregar al citado D. Antonio Colarte assi de aquella de mitad de ganancias que le perteneciere de oro q los é recivido luego yncontinente aquí en sevilla llanamente y sin pleyto alguno sin aguardar á dicho ningun plazo ni termino y lo mismo á de subceder con las deemas remesas de ganancias q en el intermedio le hiziere pues todo ello queda de mi quenta costa y riesgos por lo q consiento se me pueda executar por todo rigor de drô y dia executaba en virtud de esta Escriptura y el juramento de la ptê de dicho D. Antonio, sin mas prueva=y vajo de la misma via executiva yo dicho $\mathrm{D}$. Antonio Colarte me obligo a que en caso q los tales empleos y ventas que con mi consentimiento se hisieren por dicho Pedro Diaz de la Cruz según las quentas q viene verificando por mas de no haver resultado ganancias á no pedirle ninguna de ellas, por quanto se verificara no haverlas».

25 Ponti / Piana, AHPS, legajo 2893, p. 516, Sevilla, 1779: «Sepase como Jph Ponti y Julio Piana vecinos de esta Ciudad de Sevilla huespedes de la fonda el Leon de Oro. Y decimos q por q teniedo como tenemos invertido 
inclina por la expresa adjudicación de alguna suma pecuniaria obtenida al liquidar ${ }^{26}$. La fábrica anónima El Betis, en virtud de la naturaleza de los bienes aportados, establece una doble solución: en primer lugar, el reparto entre los socios de los bienes partibles por su naturaleza, como las hilazas; en segundo lugar, la formación de lotes equivalentes de los bienes indivisibles, a sortear entre los accionistas ${ }^{27}$.

La fórmula jurídica de la copropiedad conoce en la práctica sevillana diferentes modulaciones, estableciéndose en la escritura que, a pesar de pactarse la comunidad de todo lo adquirido en nombre de la sociedad, un determinado socio reserve para sí la futura propiedad, previa tasación y resarcimiento a los consocios del valor de los bienes comprados durante el transcurso de la compañía ${ }^{28}$. De todas formas, resulta difícil la adscripción de algunas escrituras a alguna de las categorías anteriores; así, en el contrato de Clemente Fernández y Sobrino se da una forma híbrida, toda vez que el contrato previene, según la naturaleza del bien, la reserva dominical de los inmuebles, donde se desarrolla la actividad comercial y el reparto a prorrata de los géneros, los efectos y los créditos que «en aquel tiempo haya en esta Dependencia $\rangle^{29}$.

nuestro Caudal en dicha fonda, la que con este motivo hemos estado manejando htâ aquí, higualmente en la consideracion de ser higuales la ptê de ynteres q cada uno tenemos en ella, y por quanto hasta aquí nos hemos llevado. Otorgamos que hacemos y formamos Comp ${ }^{\mathrm{a}}$ en el dicho trato y Cassa de fonda por tpô de tres años que empiezan a correr y contarse desde primero del presente mes de Julio y año de la fecha en adelante durante el qual dicho tpô hemos de permanecer unidos como htâ aquí con higual voz accion, y govierno, el uno q el otro: en cuio yntermedio el fondo prâl que produxere dicha Casa sean de pagar sus arrendamientos, y abastecer de lo necesario de comestibles $\mathrm{p}^{\mathrm{a}}$ su consumo, y todo lo deemas q por razon de dicho manejo ócurra pagarse, y satisfacerse, alimentando de comestibles su Casa y familia en higuales terminos, y en esta conformidad sea de seguir hasta conclusos dichos tres años, bien entendido q en fin de cada un año hemos de formar balanse de todos los enseres muebles, y peltrechos, y comestibles q en dicha Casa tubieremos $\mathrm{p}^{\mathrm{a}} \mathrm{q}$ con esta regla y conocimiento procedamos con el mayor acierto, y en fin de los citados tres años si nos quisieremos separar lo podamos hacer libremente perciviendo cada uno la mitad del liquido q importare dicho Caudal, despues de haver pagado y satisfechos todas quantas deudas se haran contraido, y devengado: y lo mismo sucediera, en el caso de falleciera qualquiera de los dos en el intermedio de esta compañía pues incontinente: se executara dicho valanse, y entregará dicha mitad, a los herederos del q de nos falleciere».

26 En este sentido, ha de matizarse la posibilidad que reconoce la doctrina, en concreto, González Huebra sobre la admisibilidad que el capital de la sociedad anónima pueda ser compuesto por bienes o géneros de cualquier naturaleza no pecuniaria. Sobre esta cuestión Pablo González Huebra, Curso de Derecho Mercantil, Madrid, pp. 154-156.

27 El Betis (Fabrica anónima de Lienzos), AHPS, legajo 6595, fol. 780, Sevilla, 1845: «17 . A la terminación de este contrato en el caso que no conviniera á alguno ó á todos los Socios ampliando por mas tiempo se hara la partición por partes iguales tanto de lienzos como de hilazas, [...] y demas enseres y como algunas cosas habrá que no eran partibles como es la calandria en este caso se harán dos lotes de tornos, telares o tambor que balgan lo mismo que la calandria para que con esta formen tres: estos se sortearan y al que le toque tendrá que conformarse con el que sea sin mas reclamación pues desde ahora renuncian los tres a todas».

28 Carbajo / Planelles, AHPS, legajo 3830, fol. 1220-1222, Sevilla, 1826: «6 $6^{\mathrm{a}}$. Que si cuando dispusieremos la conclucion de esta compañía se hubieren comprado algunos efectos de cuenta de ambos socios antesediendo que yo el Carbajo sea reintegrado a lo que tenga supliome quedare con los citados efectos pagando por tasacion de Peritos cuota que corresponda â mi el tomas Planelles que todo ello hace resultas por los apuntes que llebemos ambos»».

29 Clemente Fernández y Sobrino, AHPS, legajo 1969, fol. 581-583, Sevilla, 1831: «DECIMOS; Que de algún tiempo a esta parte hemos estado en Compañía, en el trafico, y negociación de un refino, y Almacen de Comestibles [...] de esta Ciudad en la Collación de San Andrés en una Cassa Señalada con el numero once del gobierno, cuya propiedad de esta corresponde, a Doña Rosa Crespi, y el citado establecimiento al dicho D. Clemente, y para que esta Sociedad siga girando con la debida formalidad nos hemos propuesto celebrar esta Escritura a mitad de perdidas y ganancias en el giro y trafico del citado Refino y Almacen de Comestibles en las Cassas Numero Once Venexa, por tiempo y espacio de dos años que empezaron a contarse en el día Doce de Abril de 
Como tercer y último supuesto respecto de la titularidad del capital nos referimos a la reserva de la propiedad de algunos de los efectos o de las cantidades entregadas. Si bien Eugenio de Tapia entiende el caudal común como un derecho real del socio ${ }^{30}$, a partir de la codificación se aprecia la nueva percepción de la sociedad como persona jurídica con sus derechos patrimoniales y sus correlativas obligaciones.

La reserva de la propiedad de algún bien aportado al capital social por parte de algún socio puede obedecer a una pluralidad de motivos: la naturaleza del bien, el modo en que es entregado y la proporcionalidad entre las aportaciones, sin prescindir del tipo asociativo escogido para la constitución de la compañía.

Según las cualidades del bien entregado, la práctica y la doctrina más cualificada entienden que el socio que entrega el bien conserve su propiedad en detrimento del socio exclusivamente industrial ${ }^{31}$. Un claro ejemplo lo ofrece Pardessus en relación con las empresas de diligencias, cuya liquidación ocasiona la devolución a los socios de aquellos bienes conferidos (generalmente caballos y coches) en el momento constitutivo de la sociedad, pues se considera que solo se entrega el uso, no así la

mil ochocientos treinta y uno, deviendo cumplir en el día once de Abril de mil ochocientos treinta y tres. Para cuyo establecimiento perteneciente al citado Don Clemente Fernández; tenemos puesto por fondo de él, cincuenta y un mil setecientos y ocho Reales Vellón, con esta distinción los treinta y nueve mil quinientos quarenta y un Reales correspondientes del mismo Don Clemente, y los doce mil ciento sesenta y siete restantes tocan en propiedad al referido Don Francisco Fernández Suarez, según el balance que ultimamente hemos hecho y obra en nuestro poder [...]. El primero que de los fondos de esta compañía se han de pagar todas las contribuciones que por ella se caussen, como también la renta de la cassa, en que está establecida ésta Dependencia, y lo que tenemos asignados a el Dependiente que tenemos para su despacho; sentandose estas Partidas conforme se bayan satisfaciendo en el Libro de Data para su abono a su devido tiempo en la Cuenta General. [...] El cuarto que la Cassa en que está establecida dicha Dependencia, continuaria escriturada a nombre del recordado Don Clemente Fernández con el fin de que a la separación de esta Sociedad, quede éste con el giro de la citada Dependencia. El quinto que a la Disolución de la actual Compañía, tomaremos cada uno de nos, ambos socios en cuanto y parte de pago de nuestro respectivo haver, aprorrata en proporción, las Especies de Generos efectos, y Creditos que en aquel tiempo haya en esta Dependencia».

30 Eugenio de Tapia, Elementos de jurisprudencia mercantil, considerablemente aumentada, y refundida con arreglo al nuevo Código de Comercio de 1829, Valencia, Librería de D. Ildefonso Mompié de Montagudo, 1838 , p. 88.

31 J. M. Pardessus, Cours de droit commerce, núm. 990, pp. 488-490, considera que la compañía actúa en concepto de mera usufructuaria, puesto que el socio capitalista aporta la explotación del bien aportado. Es el caso de Juan Borreguero y Compañía, AHPS, legajo 1340, fol. 540, Sevilla, 1751: «Que otorgamos compañía para tenerla por tiempo de dos años y siete meses que empezaron a contarse desde el primero del corriente de diciembre, en los utiles que produjeren unas Cassas Hornos y Pan coser que son en esta ciudad, al sitio de la Encarnación vieja Propias del Convento de las Religiosas de la Pasión de ella que yo el Joseph Truxillo tengo en arrendamiento cuya compañía establecemos bajo nombre de Juan Borreguero y Compañía con los capítulos siguientes: Lo primero que yo el dicho Juan Borreguero durante el tiempo de esta Compañía e de correr con la administración de la referida Cassa Horno y Pan y es detener el Libro de Cuenta y Razón de los gastos publicos y privados que los huviere para darle cual expresado mi compañero siempre que me la pida porque así estamos de acuerdo. Lo segundo yo el referido Joseph Truxillo e de suplir de mi propio Caudal a los vecinos Panaderos que viven y vivieren en dichas Casas Hornos de Pan coser las cantidades que fuere mi voluntad estando el acuerdo con el referido Juan Borreguero y el importe de los gastos que se ofrecieren para la administración siendo de quenta y riesgo de ambos por mitad la perdida que huviere en el suplemento porque asi estamos de acuerdo. Lo tercero que esta Compañía se establece a perdidas y ganancias por mitad igualmente de forma que cumplido los referidos dos años y siete meses se debe ajustar la quenta de ella y basados todos los gastos y costos que se huvieren causado si huviere utilidades es de llevar yo el dicho Joseph Truxillo la mitad por razon de los suplementos que huviere hecho y de estar a mi nombre las mencionadas Casas Hornos yo el expresado Juan Borreguero la otra mitad por causa del trabajo y ocupación de la otra administración y si huviere perdidas en la misma conformidad an de ser de quinta y mitad de ambos otorgantes porque asi estamos de acuerdo». 
propiedad; en la Sevilla del período analizado encontramos este supuesto en la sociedad Vicedo / Calero / Carrasco / Lerrezuelo / Merlo ${ }^{32}$.

Otro supuesto reflejado en los contratos sevillanos es aquél en el que el socio capitalista se limita a aportar una cantidad pecuniaria al objeto de que se continúe con la actividad comercial que se le ha de reintegrar cuando se disuelva la compañía junto con la parte de beneficios que le corresponda, es el caso de la sociedad Ramón Torrijos, donde el abogado Dr. Nicolas Bastida entrega una suma cuyo reembolso prevé la escritura con carácter previo al reparto de los beneficios ${ }^{33}$. Un supuesto que también se produce en la disolución de la sociedad De Torres / Medel / Sánchez, donde los compañeros de industria devuelven el caudal proporcionado por el único socio capitalista, Gerónimo de Torres ${ }^{34}$.

32 Sobre esta cuestión se extiende J. M. Pardessus, quien distingue entre este tipo de sociedades y aquellas destinadas para el cuidado y la monta de caballos, en las que entiende que no ha de devolverse los caballos a los socios de la compañía, Cours de droit commercial, núm. 990, pp. 488-490. Para la práctica sevillana, Vicedo / Calero / Carrasco / Lerrezuelo / Merlo, AHPS, legajo 1976, fol. 334, Sevilla, 1835: «Que teniendo el primero una Calesa y un Carro, el Segundo una Calesa, el Tercero un Carro, el quarto una Calesa, y el quinto una Calesa, con cuyos Carruajes portean las Arrobas y Bagajes que se le proporcionan desde esta Ciudad hasta la Villa y Corte de Madrid, su carrera y ciudad de Cadiz, y queriendo no causarse perjuicio unos a otros, han determinado sentar compañía que establecen y sienten compañía en dichos Carruajes para transportar arrobas y bagajes desde la Villa y Corte de Madrid a esta Ciudad de Sevilla y su Carrera y Ciudad de Cádiz respectiva digo por tiempo de un año que empezará contarse en el día veinte del presente mes de Mayo de esta fecha, y cumpliran igual día y mes de el que viene de mil ochocientos treinta y seis; durante cuyo tiempo hemos de trabajar todos igualemente con nuestros respectivos Carruajes sin falta ni excusa alguna, haciendo todas las conclusiones y Portes que se ofrezcan tanto a unos como a otros. La primera que todas las arrobas que se conduzcan por todos o cualesquiera de los cinco compañeros desde esta ciudad a cualesquiera de los puntos detallados en esta Escriptura, o desde aquellos a esta Ciudad y su Carrera han de ser puesto a un precio a el tiempo que se reparta su producto entre todos en cada liquidación, pues aunque sean de mas o menos se han de nibelar para que todos los cinco compañeros percivan igual interes, el que se habrá de repartir en la Villa y Corte de Madrid o en la Ciudad de Cádiz precisamente en cada viaje, perciviendo cada uno de los cinco interesados la cantidad respectiva a lo que haya porteado con su Carruaje, sin poder exigir mas cuota ni compensacion, a todo lo que se les ha de poder recombenir respectivamente en forma legal».

33 Ramón Torrijos, AHPS, legajo 1986, fol. 190-192, Sevilla, 1842: «El Dr. D. Nicolas Bastida y Molina, Abogado de los Tribunales de la Nacion y del Ilustre Colegio de esta misma Ciudad, y D. Ramon Ruiz Torrijos, Maestro Sombrero de esta vecindad, á quienes doy fé conozco y dijeron, que habiendo determinado establecer compañía en el trafico y negociacion de sombreros de felpa y fieltro, en una tienda que con este objeto han de abrir, en una Casa demorada situada en esta Capital en la Calle de las Sierpes numero once de gobierno queriendo para seguridad de ambas partes elevarlo á documento publico: Otorgan que establecen y sientan compañía en la espuesta negociacion, á mitad de perdidas y ganancias, por tiempo y espacio de cuatro años, contados desde el primero de mayo proximo del presente de la fecha [...] 2a Que el capital de esta sociedad ha de ser el que el D. Nicolas entregue al D. Ramon, para la compra de felpa y demas efectos necesarios, tanto en metalico como en efectos indispensables, todo lo que resultará de un libro de caja que con este intento se há de formar, el que se firmará por el recipiente, y rubricará el capitalista. $9^{\mathrm{a}}$ Que cuando se disuelva esta compañía, se dividirán por mitad los generos y caudal que hubiere existentes, deducido el fondo del capital aportado por el D. Nicolas aplicándose á cada uno igual porcion, en efectos buenos, medianos, y malos sin que bajo ningun pretesto pueda pretenderse otra cosa en esta razon, y si hubiere perdidas nada perderá el socio de industria, mas que su trabajo personal».

34 Cancelación de la compañía De Torres / Medel / Sánchez, AHPS, legajo 1981, fol. 138, Sevilla, 1825: «que por escriptura por otorgamos ante el año de mil ochocientos veinte y tres, por la sentamos aparceria por terceras partes de perdidas y ganancias en el trafico y negociación, de comprar y vender ganados de todas clases para el Matadero de esta ciudad, la qual sentamos por el termino de un año que empezó a contarse en primero de Abril de el dicho año de mil ochocientos veinte y tres; Cuya compañía duró hasta el año de mil ochocientos veinte y cinco en que terminó de acuerdo de nos todos tres: para qual puso yo el Torres por fondo quince mil Reales de Vellón y nos Sanchez y Medel solo nuestro trabajo e industria que para la seguridad de las cantidades que entraren en poder de los dichos Sanchez y Medel ademas de las obligacion general de bienes y rentas habian de 
Según se adelantó, una cuestión fundamental para la titularidad de las aportaciones realizadas como capital es la tipología social. Las sociedades de capital se resuelven en una fórmula jurídica destinada a la separada titularidad de la participación. La propia estructura de la sociedad en comandita reserva al comanditario la propiedad de los bienes aportados en el momento de la liquidación, como puede observarse en Agustín Henkes y Compañía ${ }^{35}$.

La naturaleza de la sociedad anónima permite a los accionistas disponer y negociar con su acción, una vez que se haya desembolsado ${ }^{36}$. Una cuestión distinta se refiere a la posibilidad de que los acreedores de los socios puedan embargar su parte de interés. J M. Pardessus considera que los acreedores de los socios de una compañía general deben esperar a la liquidación final para que puedan hacer efectivo su crédito, mientras que, en las sociedades anónimas, el acreedor de un socio puede exigir la venta de las acciones para la ejecución de una deuda ${ }^{37}$. La escasez de socie-

obligar como con efecto obligaron el Don Rafael Medel tres aranzadas de Olivar que le pertencian en termino de la Villa de Cantillana al sitio de Valde Infierno; y el Francisco Sanchez un pedazo de tierra calma termino de las misma Villa en la Vega de Vidal [...] para no poder las venderlas hasta estar reintegrado al Geronimo de Torres de todas las cantidades que tubiese desembolsadas, y chancelada dicha compañía, que asi con mas expresion aparece de la citada Escriptura y haviendo reintegrado yo el Geronimo de Torres de los quince mil reales que puse por fondo de ella, hemos decidido chancelar aquella escriptura, y para que se berifique de un modo solido qual corresponde, por el tenor del presente documento que Geronimo de Torres doy Carta de Pago a favor de los repetidos Don Francico Sanchez y Don Rafael Medel del los consavidos quince mil reales Vellón que puse por fondo en metalico para la expresada Compañía [...] y nos los recordados Don Rafael Medel y Francisco Sanchez tambien por estar reintegrados de mi a tercera parte de utilidades de su importe nos damos de el por entregados a nuestra voluntad sobre que renunciamos las expecificas leyes».

35 Agustin Henkes y Compañía, AHPS, legajo 2971, fol. 464-468, Sevilla, 1844: «Que habiendo tenido el difunto D. Francisco Sanchez establecimiento de Quincalleria y Cristal en esta Capital que han convenido en continuar el mencionado giro [...]: Otorgan que forman sociedad, que se titulará Agustin Henkes y Compañía para el comercio de quincalla Cristal y demas efectos por el tiempo de seis años [...]. Primera. Para el fondo D ${ }^{\mathrm{a}}$ Maria del Carmen aportará como socia en comandita, la suma de sesenta mil reales de vellón, que pondrá á disposición del D. Agustin Henkes cuarenta mil en los efectos de Quincalleria y Cristal que le pertenecen por suerte del nombrado Su Marido, y los veinte mil restante á pagar de buena forma á su vencimiento en Mayo y el D. Agustin lo hará de la cantidad que resultan por sus recibos que á su favor, y con referencia á este contrato la facilitará la $\mathrm{D}^{\mathrm{a}}$ Maria del Carmen, el que se tendrá como parte esencial de esta escritura. Segunda. Para los efectos de Cristal y Quincalla que aporta la $\mathrm{D}^{\mathrm{a}}$ Maria del Carmen se le entregara al D. Agustin bajo los respectivos valores que le fueron adjudicados á aquella por muerte de su Socio, y á su disolución los recibirá bajo el mismo tipo, advirtiendo que sin sus aprecios no alcanza á cubrir los cuarenta mil reales de vellón que quedan marcados, queda obligada la D ${ }^{\mathrm{a}}$ Maria del Carmen á entregarle lo que falta hasta su completo en efectivo metalico. [...] Quarta. Que mediante á quedar á disposición del D. Agustin el capital aportado por la indicada Señora á la sociedad para su libres manejo, queda responsable á devolverlo á la finalización de esta compañía, con el aumento que le pertenezca de las ganancias, ó descuento de las perdidas si apareciesen».

36 González Huebra distingue en la compañía anónima entre el capital nominal, que es el total o maximun que compone el fondo social, y el capital efectivo, que es la parte de capital que se desembolsa efectivamente y que entra en la caja de la sociedad, siendo este último el único que puede ser representado por títulos o cédulas para su circulación en el comercio; Curso de derecho mercantil, pp. 154-156. La tesis se inspira en los preceptos del Código de Sainz de Andino que prohíben la emisión de «cédulas por valores prometidos», quedando el accionista obligado ante la sociedad por el importe que falta del capital suscrito: Código de Comercio 1829, art. 280: «Las acciones de los socios en las compañías anónimas pueden representarse para la circulacion en el comercio por cédulas de crédito reconocido, revestidas de las formalidades que los reglamentos establezcan, y subdividirse en porciones de un valor igual»; y art. 281: «Estas cédulas no podrán emitirse por valores prometidos, sino por los que se hayan hecho efectivos en la caja social antes de su emision. Los consignatarios de las cédulas que se espidan, sin que conste de los libros de la compañía la entrega del valor que representan, responden de su importe á los fondos de la compañía y á todos los interesados en ella».

37 J. M. Pardessus, Cours de droit commerce, núm. 973-975, pp. 477-480. 
dades anónimas, así como de sus reglamentos, imposibilita conocer la forma en que se desarrolla la casuística a este respecto. Consta al menos, que las acciones de la Real Compañía de San Fernando tenían la consideración de bienes raíces, pudiendo ser vinculadas o amayorazgadas ${ }^{38}$.

\section{3. la determinación del capital}

La fijación del fondo común en la escritura de sociedad reviste vital importancia. Los proyectos de ordenanzas y las propias ordenanzas consulares manifiestan su preocupación por la exacta determinación del capital aportado, en tanto que los códigos prolongan este afán por controlar la cuantía de la masa económica de la sociedad. El proyecto de ordenanzas del Real Tribunal de Cádiz muestra especial sensibilidad a la detracción de fondos de la compañía, porque el abuso podría causar el impago de los créditos contraídos contra la misma, especialmente cuando la cantidad detraída se haya destinado a negocios particulares, alterando sustancialmente la realidad económica de la compañía ${ }^{39}$. Méndez y Balcarce reproduce la prohibición legal de distraer los recursos de la sociedad con destino a los «negocios particulares u otros fines que no estén capitulados en la escritura», bajo pena de devolver la cuantía detraída junto con los daños ocasionados ${ }^{40}$.

Pedro Sainz de Andino no altera la prohibición del proyecto gaditano de retirar una mayor cantidad para los gastos que los pactados por los socios ${ }^{41}$. González Huebra disiente de la solución dada por el Código para los supuestos de retirada de sumas superiores a las pactadas para gastos. El autor considera que la prohibición no ha de reducirse a los «gastos del socio o de su familia», sino que ha de extenderse a los recursos empleados «con otros fines lucrativos», debiendo imponerse al socio la obligación de restituir las ganancias obtenidas con el capital de la sociedad y otorgando a los restantes la posibilidad de rescindir el contrato, «porque cesa la razón que ha tenido la ley para tratarle con más consideración e imponerle menos pena» ${ }^{42}$. Además, los autores anteriormente citados subrayan el valor del consentimiento de los restantes socios para poder retirar los fondos, un requisito que cumple la práctica sevillana a tenor del elevado número de escrituras que mencionan la inexcusable conformidad de todos los socios a qué, tal como se produce en las sociedades de

38 En este sentido, Carlos Alberto González Sánchez, La Real Compañia de Comercio y Fábricas de San Fernando de Sevilla (1747-1787), Sevilla, Biblioteca de Temas Sevillanos-Ayuntamiento de Sevilla, 1994, p. 20-23.

39 Proyecto de Ordenanzas del Real Tribunal del Consulado de Cádiz 1800, trat. 4, tít. 2, ley 74: «Establecida el fondo de una sociedad ninguno de los socios podrán extraer cantidad alguna para usos particulares, y el que lo hiciere no solo quedará responde á ella, si es â los daños que le siguieren».

40 Ramón Méndez y Balcarce, Instituciones y doctrinas de Comercio, Buenos Aires, Instituto de investigaciones de historia del Derecho, 2000, p. 25.

41 Código de Comercio 1829, art. 317: «Ningún socio puede segregar ni distraer del acerbo comun mas cantidad que la que se hubiere designado á cada uno en las sociedades colectivas ó en comandita para sus gastos particulares; y si lo hiciere, podrá ser compelido á su reintegro, como si no hubiese completado la porcion de capital que se obligó á poner en la sociedad, ó en su defecto será lícito á los demas socios retirar una cantidad proporcional, segun el interes que tengan en la masa comun».

42 González Huebra, Curso de derecho mercantil, p. 142. 
González y Fernández ${ }^{43}$, en Merediz, hijo mayor, y Espejo, Compañía ${ }^{44}$-donde se incluye el acuerdo en el libro de actas de la sociedad para que pueda tomarse la cantidad acordada- y en Galán / Sánchez ${ }^{45}$.

La práctica sevillana acepta, comúnmente, la licitud de la detracción de los fondos para hacer frente a los gastos necesarios que posibiliten la continuidad de la compañía y la consecución del objeto de comercio ${ }^{46}$, e incluso, si la disposición de fondos tiene como finalidad el suministro de los recursos necesarios para que el socio industrial pueda sobrevivir ${ }^{47}$.

43 González y Fernández, AHPS, legajo 6539, fol. 463-466, Sevilla, 1819: «7ª Que yo el Franc. Fernandez podré sacar del fondo principal de esta Comp ${ }^{\mathrm{a}}$ seis reales de vellon diarios sin que se me carguen en Cuenta. $8^{\mathrm{a}}$ Que si algunas de las expresadas dos partes necesitare tomar algunos intereses del fondo de este establecimiento deberá ser con acuerdo de ambas, para formalizar Documento que sea de abono á su finalización».

44 Merediz, hijo mayor, y Espejo, Compañía, AHPS, legajo 2934, fol. 14-18, Sevilla, 1816: « $5^{\circ}$ Que tanto el Sueldo ó Salario del dicho Segundo Director como los jornales de los dichos, operarios que se pongan en la citada fabrica ó se aumentaren lo subsecivo, según las faenas se ofrescan en ella, havian de ser pagados y satisfechos al final de cada semana: tanto el aumento de operarios como el de los Jornales de estos y el Sueldo del Segundo Director han de ser precisamente con acuerdo y conformidad de ambos Socios [...]. $18^{\circ}$ Que cada qual de los referidos socios podrá sacar para sus urjencias aquella cuota o porción que necesite con la cualidad precisa de haver de apartarse la cantidad ó cantidades que se sacasen del fondo de la compañía, en el Libro de Caxa destinado para su mejor reximen».

45 Galán / Sánchez, AHPS, legajo 2933, fol. 231-233, Sevilla, 1815: « $5^{\circ}$ Que las compras de Generos por el Surtimiento de la Casa ha de ser con presencia ó consentimiento de ambos Socios. $6^{\circ}$ Que dicho D. Felix Galan le acomode poner algun mas fondo en el importe de Generos de pronta Salida lo ha de poder hacer, cargándose la cantidad que esto ascienda por mas capital el respectibo [...]».

46 Son innumerables los supuestos de sociedades que detraen las cuantías oportunas para afrontar los gastos propios de la actividad de la compañía: Saravia / Parreño, AHPS, legajo 1978, fol. 599, Sevilla, 1836: «Y la diez que los sueldos que se han de pagar a cada uno de los recaudadores, Dependiente de Escriptorio y demas que acaso sean necesarios, han de ser satisfechos por la misma Compañía, como también lo serán todos los demas gastos que ocurran en ella, hasta que llegue el caso de dejar chancelada Escriptura de obligación Hipotecaria y en libertad las fincas»; Malcampo / Marrugal, AHPS, legajo 2915, fol. 519-520, Sevilla, 1799: «Que de dicho, fondo no solo se han de haser los empleos de tierras y deemas efectos [...] de dichas zarasas, y estampadas sino también [...] los salarios á los operarios que en ella se ocuparon y renta de la casa de mi estado y demas gastos»; González y Fernández, AHPS, legajo 6539, fol. 463-466, Sevilla, 1819: «El primero que de los fondos de esta compañía se han de pagar todas las contribuciones que por ella se caussen, como también la renta de la cassa, en que está establecida ésta Dependencia, y lo que tenemos asignados a el Dependiente que tenemos para su despacho; sentandose estas Partidas conforme se bayan satisfaciendo en el Libro de Data para su abono a su devido tiempo en la Cuenta General».

47 Don José Pevidal y Compañía, AHPS, legajo 1851, fol. 520-523, Sevilla, 1823: «Otorgamos que establecemos sentamos y fulminamos a terceras partes de utilidades, en el tráfico, y negociación de un Almacen de Quincalla, comestibles y otros renglones, propio de mi dicho Don José Pevidal, el que está arreglada, y puesto en unas Casas en la Alcayceria de esta Ciudad cuia sociedad empezó a correr, y contamos en el día 21 Octubre de 1822, y terminará en el mismo día del que viene de 1824, para el que yo el D. José Antonio Pevidal he puesto por fondo la cantidad que se expresará, y yo el D. Alejandro he puesto mi industria, y trabajo personal en cuio tiempo hemos convenido ambos en guardar cumplir [...] El cuarto: Que el Don José Pevidal como dueño del capital o certa Dependencia, llevará para si las dos terceras partes de las utilidades que Dios nuestro Señor fuere servidos darnos en otro tiempo; y la tercera parte restante la llevará para si el Don Alejandro respecto a industria, y trabajo personal, como también del celo con que se ha de comportar en el mejor fomento de esta dependencia: Quedando prohibido a uno, y otro socio sacar nada de ella hasta el fin de los dos años de su establecimiento, ni podrá pedir ni sacar el Don Alejandro mas que lo preciso para su decente vestuario, y sucinto socorro para la manutención de su anciano padre. [...] El octavo: Que la manutención del dicho Don Alejandro Rubio, y Dependiente, durante dicho tiempo estará al cuidado de mi el citado Don José Pevidal abonandome por esta sociedad cinco reales de vellón diarios por la de cada individuo incluso el lavado de ropa cuio pago se me hará en efectivo al fin de cada año, sacandolo de la masa común de este establecimiento». El modo en que se regula el abono de los gastos del socio de industria con el caudal común debe interpretarse como pago más que permite 
Por otra parte, los contratos sevillanos, amparados en la libertad contractual propia del derecho mercantil, también contemplan una amplia variedad en la forma en que han de retirarse las sumas del fondo de la compañía, lo que puede oscilar desde la simple retirada del capital aportado ${ }^{48}$, al anticipo por parte de uno de los socios a cuenta de futuras ganancias ${ }^{49}$, aunque cabe la posibilidad de que se produzcan ambos sistemas, como sucede en la compañía Abad / Parra ${ }^{50}$, sin olvidar otras modalidades, como tomar alguna cantidad para ser devuelta con el correspondiente incremento de

el mantenimiento del objeto social. Es el caso de Rafael Ruiz y Compañía, AHPS, legajo 1400, fol. 189-192, Sevilla, 1845: $" 4^{\circ}$ Los gastos en que queda agravada la dependencia consistiran en el pago de contribuciones que el gobierno se designe arrendamiento de Casas Salarios de dependientes y la manutención de estos a razon de siete reales diarios por cada uno en los cuales van inclusos el gasto de ropa limpia y demas en que incurran aso como tambien los portes de Cartas. $5^{\mathrm{a}}$. Es de cuenta del establecimiento las obras de arvañileria carpinteria alumbrado, pintura y demas que exija su buen estado y perspectiva quedando todos los enseres a beneficio de la masa comun disuelta que sea. [...] 13 $3^{\text {a }}$. Cada fin de mes se hara balance de Caja y el efectivo que aperezca para reintegro a poder del socio capitalista quien entregara del industrial lo necesario a cubrir las obligaciones mensuales que pesan sobre el establecimiento. $14^{\mathrm{a}}$. Y el socio industrial le entregara ademas el capitalista seiscientos reales mensuales para su manutención en y a suma al debito de su cuenta corriente pues se concedera como un adelanto. [...] 16 ${ }^{\mathrm{a}}$. Ademas de los seiscientos r. v. retira a cuenta el socio industrial inicialmente podra tambien este resibir a cuenta de su haver lo demas que necesite $\mathrm{p}^{\mathrm{a}}$ sus gastos particulares en fin de cada año no excediendo de cino mil reales vellón»; o por último, Felipe García y Compañía, AHPS, legajo 1980, p. 283, Sevilla, 1837: «La quinta: que todos los gastos comunes de la dependencia como son, dependientes, arrendamientos de casa, y contribuciones, y otros gastos que ocurran, han de salir de la masa comun de la Compañía, como también la manutención del Don Felipe Garcia, no excedienda esta de ocho Reales de Vellón diarios, llevando a efecto este la oportuna cuenta y razón».

48 Son casos que hemos expuesto anteriormente y que citamos sucintamente a efectos de no extendernos en demasía: González y Fernández, AHPS, legajo 6539, fol. 463-466, Sevilla, 1819, o Saravia / Parreño, AHPS, legajo 1978, fol. 599, Sevilla, 1836.

49 Esta manera linda entre el aumento de capital y la propia detracción de capital, ya que se adelanta un capital a la espera de una hipotética obtención de ganancias. Es el caso de las sociedades Monasterio / De León, $A H P S$, legajo 2887, fol. 748-749, Sevilla, 1772: «[...] con la que queda hecho dueño de la mitad de la referida tienda Generos, y peltrechos existentes y la otra mitad que assi corresponden esta me la habrá de satisfacer dicho Don Joseph en fin de dicha compañía en los mismo Generos y peltrechos en q queda radicada, y durante el dicho año de ella, yo dicho Don Joseph, me é de mantener con lo que ella predixese a el respecto de cinco r.v diarios, y no nig pagando tambien la renta mensual de la cassa donde esta al respecto de veinte $\mathrm{r}$ y medio $\mathrm{v}$ cada mes y assi mismo el ymporte de las alcavalas multas, y demas requerimientos de todo lo qual é de llevar quenta y razon formada para que concluso el dicho año se haga el Deudo valanse teniendose en él»; D. Carlos Solaxo Coene y Compañía, AHPS, legajo 2877, fol. 12-14, Sevilla, 1762: «Que para el viaxe pactado por mi el dicho, D. Enrique Coene que á de empesar á correr el mes despues de nuestro establecimiento; yo el D. Carlos Solaxo le é de suministrar á el referido los reales que nesesite para su costo al tiempo q los nesesite: con la condicion qá la vuelta dicho, d. Enrique me á satisfaser la mitad de lo que hubieren Ymportado por corresponderme mediante lo estipulado á lo que á cada uno de nos se nos á de poder obligar a la misma conforme».

50 Abad / Parra, AHPS, legajo 2932, pp. 70-74, Sevilla, 1813: «Q yo el Manuel Abad ademas de la parte de capital que entro en el fondo y que pongo mi industria y trabajo por esta causa estamos combenidos ambos socios en que se saquen $\mathrm{p}^{\mathrm{a}}$ mis alimentos siete rr vv diarios, pudiendo adatarlos en cuenta yo el propio D. Manuel Abad. Q yo el Manuel Abad ademas de la parte de capital que entro en el fondo, pongo mi industria y trabajo por esta causa estamos combenidos ambos socios en que se saquen $\mathrm{p}^{\mathrm{a}}$ mis alimentos siete rr vv diarios, pudiendo adatarlos en cuenta yo el propio D. Manuel Abad. Que la curacion de los achaques y enfermedades me sobrebengan á mi el citado Manuel Abad, durante el tiempo de los tres años de esta compañía han de salir sus gastos del fondo de ella, pudiendose cargas en Cuenta en lo q estamos combenidos ambos Socios. Es condicion que del producto de la referida compañía se ha de pagar la renta de la casa, ó el sitio donde está establecida, á quien corresponda al vencimiento de sus plasos, recogiendose los requeridos correspondientes $\mathrm{p}^{\mathrm{a}}$ seguridad de ambos Socios. Que en la propia forma se han de pagar y satisfacer del fondo de dicha compañía los gastos q sobre ella se repartan por razon de las Alcabalas u otros repartimentos y contribuciones que tuviere a bien echar sobre la misma el gobierno, de todo lo qual, se deberan recoger las correspondientes Cartas de pago». 
los intereses devengados a favor de la sociedad ${ }^{51}$. A ello ha de unirse que la libertad de pactos puede incluir, igualmente, la exclusión de alguno de los socios de poder retirar sumas del capital social, como se produce en la compañía González de la Bonilla / Merino / Vallejo ${ }^{52}$.

El principio del intuitus personarum explica la minoración del caudal común por parte de un compañero para que se haga frente a los gastos de carácter personalísimo. Es la solución a la que llega la ya citada sociedad Abad/ Parra, donde el socio capitalista y tío de la esposa del consocio es autorizado a detraer los fondos oportunos que le permitan responder a los «achaques» propios de la edad ${ }^{53}$.

Concluyendo este apartado, ha de analizarse la existencia de sociedades que prohíben expresamente cualquier disminución del capital social a causa de la naturaleza del giro de comercio, como por ejemplo el comercio marítimo, donde el propio acuerdo considera factible que pudieran surgir riesgos a los que ha de responder el caudal íntegro de la compañía ${ }^{54}$.

Otro supuesto relativo a la determinación exacta del capital se refiere al aumento de capital o a su incremento por sobrevaloración de los bienes no dinerarios entregados en el momento constitutivo. Este último caso no se produce en la práctica mercantil estudiada, ya que los contratos traen aparejada la correspondiente valoración pecuniaria con independencia de que cuenten o no con un inventario.

La doctrina manifiesta pareceres opuestos sobre el aumento del capital por parte de los compañeros. Alejandro de Bacardí interpreta, en la línea de lo establecido por el Código de Comercio ${ }^{55}$, que la sociedad no tiene derecho a obligar «a ninguno de

51 D. Gregorio Martínez y Sobrino, AHPS, legajo 6549, fol. 84-87, Sevilla, 1826: «4ª Que si yo el referido D. Gregorio Martinez desmembrase algo del expresado capital hé de ser obligado como lo quedo há abonar á la enunciada Dependencia un seis por ciento á el año; y por el contrario si lo aumentase habrá de abonarme dicha Dependencia otros seis por ciento considerandonos tanto en favor como en contra de lo que se acreditará con la sola firma del referido D. Manuel Tovia Martinez para justificar los intereses si los hubiere [...]».

52 Gonzalez de la Bonilla / Merino / Vallejo, AHPS, legajo 2936, fol. 923-926, Sevilla, 1818: «12 ${ }^{\circ}$ Tambien es condición que el D. Santiago Vallejo no havia de sacar cosa alguna en el tiempo de un año de los seis porque establecían esta compañía, y si después lo necesitase se le havia de asistir con la parte que señalase, lo que se le havia de rebajar en el tiempo del ajuste de cuenta el haver que le correspondiese».

53 Abad / Parra, AHPS, legajo 2932, fol. 70-74, Sevilla, 1813: «Que la curacion de los achaques y enfermedades me sobrebengan á mi el citado Manuel Abad, durante el tiempo de los tres años de esta compañía han de salir sus gastos del fondo de ella, pudiendose cargas en Cuenta en lo q estamos combenidos ambos Socios. Es condicion que del producto de la referida compañía se ha de pagar la renta de la casa, ó el sitio donde está establecida, á quien corresponda al vencimiento de sus plasos, recogiendose los requeridos correspondientes $\mathrm{p}^{\mathrm{a}}$ seguridad de ambos Socios»».

54 Sánchez y Compañía, AHPS, legajo 2910, fol. 159-162, Sevilla, 1794: «Que será el mantener siempre existiendo los citados treinta, y dos mill pesos de á quince $\mathrm{r} v$, del fondo, y capital por quanto puede acontecer alguno de los riesgos marítimos, esternalidades, y otros contratiempos inculpables, sin verídica omicion, falta de conducta, cuidado, y aplicación pues aun poniendo el mayor celo, suelen acontecer remexantes desgracias [...] quedará reducido dicho, capital, y fondo al liquido que resultare verificado el quebranto, y por consiguiente indegnisados de su responsabilidad nos los dichos, don francisco, y don Marcelo Sanchez sin otra prueva ni averiguación que las cuentas, papeles, rasones, y diligencias con que lo acreditamos sin que por esta razon se nos haga vaxa ni descuento del interés que por ntrô travaxo o se nos asigna y lo mismo á de observar aun quando los tales generos, que naufraguen estén asegurados». No obstante, María Guadalupe Carrasco González, Los instrumentos del comercio colonial, pp. 36-37, comenta las frecuentes aportaciones que debían entregar los distintos compañeros debido a que el sistema de flotas causaba una falta de liquidez por los viajes de los galeones que, en bastantes ocasiones, producía un elevado número de quiebras.

55 Código de Comercio 1829, art. 301: «Cuando el capital ó la parte de él que un socio haya de poner consista en efectos, se hará su valuacion en la forma que esté prevenida en el contrato de sociedad, á en defecto de pacto especial sobre ello, se hará por peritos que nombren ambas partes, segun los precios de la plaza, corriendo sus 
los socios a que entregue mayores caudales, si por falta de un mayor contingente no pudiera llevarse el objeto», debiendo éstos decidir entre la disolución de la sociedad o su continuación mediante la entrega de un suplemento por parte de cada socio ${ }^{56}$. Vicente y Caravantes se expresa en términos parecidos sobre la imposibilidad de exigir nuevas sumas al socio que aportó las cantidades pactadas ${ }^{57}$.

La práctica sevillana conoce, fundamentalmente, dos modelos para la ampliación del caudal común. El primero está compuesto por aquellas sociedades que disponen de una específica reserva de las futuras utilidades para incremento del capital social, admitiendo así la posibilidad de que se pueda responder con esos fondos a los eventuales contratiempos que surjan durante el transcurso de la vida de la sociedad $^{58}$. El proyecto de ordenanzas gaditano lo admite, y debió ser común en la práctica peninsular ${ }^{59}$.

El segundo grupo es el conformado por las compañías que, contractualmente, establecen la posibilidad de que el socio capitalista aporte las sumas necesarias para el cumplimiento del objeto de comercio o para la viabilidad de la empresa ante los problemas económicos que puedan surgir durante la vigencia del contrato como, por ejemplo, el aumento de la producción o de los gastos habidos o por pérdidas económicas $^{60}$, como es el caso de la compañía Marruella / Nieto:

aumentos ó disminuciones ulteriores por cuenta de la compañía». Previamente, el proyecto malagueño se expresa en parecidos términos. Proyecto de Ordenanzas del Consulado de Málaga 1828, art. 479: «Las mercaderías y efectos que cualquiera de la sociedad llevare a ella en cuenta de su capital se valuarán de común acuerdo por los precios corrientes de la plaza, teniéndose como dinero efectivo y la ganancia o pérdida que resulte pertenecerá a la compañía».

56 Alejandro de Bacardí, Tratado de derecho mercantil, p. 229.

57 José Vicente y Caravantes, Código de Comercio, Madrid, Imprenta de D. S. Omaña, 1850, pp. 109-110.

58 Es el caso de la compañía Prieto / Moriany donde se establece la reserva de las futuras ganancias a la espera de completar una determinada cifra de reserva: Prieto / Moriany, AHPS, legajo 6551, fol. 557-561, Sevilla, 1827 : «17 $7^{a}$ Que todos los años que dure esta compañía se há de hacer valance general con conocimiento de nos los otorgantes en los dias que señalemos de común acuerdo, de los generos, deudas en pro, y en contra, y demas caudal existente temible á la vista los mencionados Libros de Cuenta y razon que respectivamente debemos llevar, sin que ninguno de los dos suplante cosa alguna, pena de perder otro tanto de su parte de ganancias, si se verificare; y todo lo que se halle de aumento, há de ser divisible por iguales partes, pero con la indispensable circunstancia de que la que corresponda á mi el D. Joaquin Moriany há de ir quedando subcesivamente en el fondo de la compañía hasta formar un capital de sesenta mil reales v. en cuyo caso yo el D. Manuel Prieto habré de igualarme poniendo en el mismo fondo otra tanta cantidad, de manera que todo caudal en efectivo y generos ascienda á la cantidad de ciento veinte mil reales de vellon y desde entonces en adelante perciviremos respectivamente cada año la parte de utilidades que á cada uno pertenesca, sin que antes yo el Moriany pueda sacar de dicho fondo ó capital cosa alguna, salvo en los casos, y con las circunstancias que quedan expresadas»; Caso / Sánchez, AHPS, legajo 884, fol. 1315-1319, Sevilla, 1846: «6. Tan luego como esten concluidos los edificios y en producto de la negociación se liquidaran las cuentas de ellos cada seis meses escribiendolas en el libro y firmandolas y dividiendo entre si mismo la mitad de las utilidades que resulten a no ser que de comun acuerdo prefirieran dejar en fondo el todo de dicha utilidades o alguna parte de ellas para aumentos de gastos o ampliacion de la negociación».

59 Proyecto de Ordenanzas del Real Tribunal del Consulado de Cádiz 1800, trat. 4, tít. 2, ley 93: «Las utilidades que produzca el giro, y no se repartan se entenderá como capital, observándose en este punto lo dispuesto en los artículos precedentes».

60 Rafael Ruiz y Compañía, AHPS, legajo 1400, fol. 189-192, Sevilla, 1845: «16 . Ademas de los seiscientos r. v. retira a cuenta el socio industrial inicialmente podra tambien este resibir a cuenta de su haver lo demas que necesite $\mathrm{p}^{\mathrm{a}}$ sus gastos particulares en fin de cada año no excediendo de cino mil reales vellón»; D. Mariano García y Compañía, AHPS, legajo 2909, fol. 747-750, Sevilla, 1793: «Que yo dicho Don Juan é de continuar como hasta áqui dando y entregado de mi proprio caudal á otro D. Mariano todo el dinero que nesesite para dicha compañía dándome su correspondiente recivo de ellas para firmarle el cargo cada, y quando liquidemos 
« $4^{\text {a }}$ Que si fuere necesario mas fondos que los referidos cinquenta mil r. quedara a voluntad del D. Juan Marrella aumentar la suma que tenga por combeniente sin que por ello le quede presision de verificarlo pues sera de su libre advedrio hazer dicho aumento. [...] $6^{\text {a }}$. Que a la formalizacion de cada valanze solo podra retirar cada compañero las dos terceras partes de sus utilidades y en ella se ha de embever y rebaxar las partidas que en cuenta de su haver tenga recibidas quedando la otra tercera parte restante en fondo para mayor aumento de la compañía» ${ }^{61}$.

\section{Otros fondos patrimoniales de la sociedad}

El presente apartado estudia aquellos elementos patrimoniales que, sin formar parte strictu sensu del capital social, dan estabilidad económica a la sociedad y demuestra que en el período estudiado el caudal de la compañía no agota los recursos de la sociedad. Un ejemplo puede apreciarse en la escritura de Rafael Ruíz y Compañía, donde el socio industrial hace mención expresa al valor intangible de su buen crédito en la plaza ${ }^{62}$.

Otros elementos susceptibles de una valoración económica, aunque de difícil deslinde con el capital social en sentido estricto, se refieren a la aportación de reales cédulas o licencias que posibilitan la explotación de ingenios y la importación de mercancías o productos procedentes de terceros países. La sociedad Lefabre / Lugar

incluyendo en el ciento dos mill setecientos quarenta, y seis reales vellón que hasta fin de Agosto pasado de este año le tengo entregado $\mathrm{p}^{\mathrm{a}}$ el mismo efecto del tiempo anterior, y lo acreditan sus recivos que tengo en mi Poder aun que de ellos me á manifestado su distribución: en cuyo papel ú otro separado á de continuar firmando los tales recivos de las partidas que yo le vaya entregando». Existe incluso la posibilidad de que el único socio obligado a sumar unas nuevas cantidades obtenga un premio o un interés por aquellas cantidades que sobrepasen de una determinada cuantía, como se produce en la compañía Ramos / Rebolledo. Sin embargo, este supuesto el profesor Carlos Petit lo incluye dentro del apartado destinado a los otros fondos patrimoniales de la sociedad por considerarlo como un recurso ajeno al capital social y estar estrechamente relacionado con el contrato de mutuo, La compañia mercantil, pp. 126-128. Conviene citar algunas sociedades que reproducen esta dinámica: Ramos / Rebolledo, AHPS, legajo 5271, pp. 126-129, Sevilla, 1830: «Decimos que teniendo tomado yo el D. José el Asiento de Subministros de Utensilios para la Plaza de Venta, y haviendose concertado dicha negociacion ser para ambos otorgantes en sociedad bajo las condiciones, y pactos que se contendrán deseosos de elevarlo á Documento Público [...]. Lo quarto, que aunque la igualdad de participacion que queda sentada por la condicion primera que hemos concebido que el capital permanente que ha de tener en esta empresa Yo el D. José de Rebolledo sea unicamente la cantidad de ochenta mil reales de vellon, y todos los demas desembolsos que exija la negociacion han de hacer por mi el D. Francisco Ramos exigiendo el premio de seis por ciento á el año sobre las cantidades que apronte y excedan de la mitad del capital que debe corresponde». Un hecho que se repite en la única sociedad en comandita localizada dentro del corpus documental, Agustin Henkes y Compañía, AHPS, legajo 2917, fol. 464-468, Sevilla, 1844: «Primera. Para el fondo Da Maria del Carmen aportará como socia en comandita, la suma de sesenta mil reales de vellón, que pondrá á disposición del D. Agustin Henkes cuarenta mil en los efectos de Quincalleria y Cristal que le pertenecen por suerte del nombrado Su Marido, y los veinte mil restante á pagar de buena forma á su vencimiento en Mayo y el D. Agustin lo hará de la cantidad que resultan por sus recibos que á su favor, y con referencia á este contrato la facilitará la $\mathrm{D}^{\mathrm{a}}$ Maria del Carmen, el que se tendrá como parte esencial de esta escritura. Setima. Que en el caso que fuese indispensable para el giro que la $\mathrm{D}^{\mathrm{a}}$ Maria del Carmen aportarse algun capital mas, lo facilitara si lo tiene a bien bajo el oportuno resguardo, abondesele por el su cuatro por ciento anual, como si se tomase de cualquiera otra persona».

61 Marruella / Nieto, AHPS, legajo 3830, fol. 1304-1307, Sevilla, 1826.

62 Rafael Ruiz y Compañía, AHPS, legajo 1400, fol. 189-192, Sevilla, 1845: «19a. El socio industrial se valdra de su credito en la plaza $\mathrm{p}^{\mathrm{a}}$ comprar los generos que combengan pasando nota de ello al capitalista para que este cuide de su pago en sus respectivos vencimiento». 
de Andrade plantea dificultades sobre la oportunidad de considerar la real cédula que otorga la fabricación exclusiva del refino de azúcar como un bien que se introduce en el fondo común ${ }^{63}$. El supuesto de esta escritura viene a coincidir con la opinión de Alejandro de Bacardí, quien considera admisible la entrega de un ingenio o un invento como parte del capital ${ }^{64}$. Más claro es, sin embargo, el supuesto de la compañía Juárez / Piñal, cuyo giro de comercio («Cambiar y Vender Géneros Ingleses») sería inalcanzable sin la oportuna real licencia que permite la adquisición de los géneros ingleses y que, como puede apreciarse en la escritura, no forma parte del acervo común ${ }^{65}$.

Un caso que se reproduce en la práctica sevillana es aquél donde alguno de los socios confiere a la sociedad el derecho obtenido en el remate de una subasta para la que pujó, generalmente, en solitario. Estas adjudicaciones tienen muy amplios y diferentes objetos, que van desde la concesión por la Dirección General de Amortización del ex convento de San Buenaventura y el solar del derribado de San Francisco para la construcción de la Plaza Nueva de Sevilla ${ }^{66}$, el remate de un tributo para su re-

63 Lefabre / Lugar de Andrade, AHPS, legajo 2904, fol. 826-831, Sevilla, 1788: «Que yo el dicho D. Francisco Lefabre octube Real Cedula de Su Magestad, en la que se me concedio la direccion de fabrica de refinar de asucares en todo el Reyno donde y como tuviere por conveniente por termino de diez años primeros siguientes contados desde que por mi representasen á su M. las primeras muestras de Asucares Refinados [...] que é principiado á construir en esta Ciudad, y por quanto hallándome con nesesidad vigente de hacer A su ciencia de ella para pasar assi al Reyno de Francia como á otras partes á distintos asuntos que me inpiden la continuacion de dicho manejo asi por este motivo como es indispensable de tomar en calidad de las personas cavildos, comunidades, y de quienes les encontrase para el total establecimiento de dicha fabrica, causa por que se me dilatara Asunptos, para el Remedio de todo, me é comvenido con el explicado Don Domingo Lugar de Andrade en Cederle como le cedo, Renuncio y traspaso el citado privilegio, y demás Reales Cedulas que á su Consequencia é ganado ásta áqui que por el dicho tiempo de diez años contados desde que á si se presenten á su magestad dichas prímeras muestras de Asucares de dicha fabrica en adelante, y todo el tiempo que ádemas se le prorrogare siga con la direccion, manejo, Administracion, y disposición de dicha fabrica con todas las facultades, excepciones, prerrogativas, Privilegios [...] y el susodicho adquiriere, ganare de nuevo solicitando su entera conservación y manutención defendiendo su estabilidad firmeza, y cumplimiento judicial, y extrajudicialmente cada y quando que se ofresca usando de las facultades de tal único director sin mi intervención ni la de otra ninguna persona por que por ningún caso la á de tener ni yo con pretexto alguno la é de intentar mas que en los casos que ádelante serán manifestados: y en esta intelixencia á de usar con dichos Reales Privilegios y Cedulas de todas las facultades de tal director de dicha fabrica donde y como tenga por conveniente en los dominios de España, para lo que le pongo, y subrrogo en mi propio lguar grado y derecho para que le represente con general Administracion $[\ldots] »$.

64 Alejandro de Bacardí, Tratado de derecho mercantil, pp. 223.

65 Juarez / Piñal, AHPS, legajo 1946, fol. 17-18, Sevilla, 1820: «Que haviendose trahido de esta Capital porción de Géneros Ingleses con Real Licencia, nos hemos propuesto cambiar algunos para su despacho; y [...] en Compañía con ellos; y para que esta Negociación tenga la formalidad que se requiere hemos deliberado celebrar esta Escritura, y para que tenga a su devido efecto por la presente Carta en la via y forma que haya lugar en derecho. Otorgamos que establecemos, sentimos y fulminamos Compañía a mitad de perdidas y ganancias en Cambiar y Vender Generos Ingleses, en las formas siguientes. Primeramente se declara que esta Compañía ha de Iniciar con el principal de sesenta mil R. V. que pone de Capital el dicho Don Diego Juarez; y la Industria, instrucción, y trabajo, yo el Francisco Piñal con cuio objeto declaro he recibido la expresada Cantidad, y por estar en mi poder en Metalico, me doy fe ella por contento, y entregado a mi voluntad, sobre que renuncio la excepción y Leyes de la non numerata pecunia prueba del entrego, y recibo como en ellas, se contiene de que doy Resguardo en forma; bajo de cuyas sincunstancias, el sitiado Don Diego por capitalista ha de llevar, la mitad de utilidades y yo el Francisco la otra mitad, por socio de Yndustria trabajo e inteligencia; deviendo cada uno de los dos sufrir tambien de por mitad el Quebranto o perdida que a casso huviere».

66 Asociación para construir la nueva Plaza de Sevilla: un teatro cómico y demás edificios que se consideren de utilidad, AHPS, legajo 874, fol. 91-94, Sevilla, 1843: «Individuos de la Junta nombrada del derrivo del estinguido convento de San Francisco de esta ciudad elegida por la provisional de gobierno creada en setiembre del año de 
caudación en un determinado espacio geográfico, en este caso la «renta de Palmete», por parte de la Real Hacienda ${ }^{67} \mathrm{o}$ la realización de una contrata por la Real Fundición de Artillería para la escamonda de pinos en varias dehesas, pero que, debido a la imposibilidad de realizar la citada tarea en solitario, el contratista procede a constituir sociedad por la confianza que le merece su consocio en la ejecución de los trabajos ${ }^{68}$. Sin resultar de la misma influencia en la constitución de la sociedad, existen numerosos socios que prestan, sin incluirlo en el fondo común, los contratos de arrendamiento rubricados bajo su propio nombre con el fin de que la compañía ejecute la actividad concertada. Sucede en la sociedad de Carmona / Higuera / Casado/ López

mil ochocientos cuartenta: Don Juan Murphi, D. Domingo de Ayala, y Don José Alvarez y Benito, todos ellos vezinos de esta Ciudad por mi propio interes. Dijeron: que la referida Junta de derrivo o Auto en quince de Junio del año proximo pasado una Real Orden por contucto del Ministerio de Hacienda en que conformandose S. A. el Regente del Reyno con el parecer de la direccion general de Amortisacion se sirvió acceder a la solicitud que se dirigió, concedienole el ex convento de San Buenaventura, y el solar del derribado de San Francisco de esta dicha Ciudad, con el objeto de construir una gran plaza publica pero con la cualidad de que esta consecion no tendría efecto hasta que la empresa acreditase hallarse legalmente constituida en sociedad anonima por escritura publica y demas formalidades del caso: que assi entonces ha de entenderse hecha la consesion á censo con el canon anual de tres por ciento sobre el valor en tasacion del solar y materiales, y que la sociedad ha de garantizar el pago de dicho censo; así como del de quince reales veinte y ocho maravedis anuales que hoy gravita sobre los mismos edificios con hipotecas satisfactorias á reserva de que a su tiempo respondan de ambos gravamenes las casas que en la misma plaza se construyan, y que han de ser su hipoteca material. Que deseando los comparesientes establecer esa sociedad que desea el gobierno para definir á la convesion de los conventos, en cuyo lugar ha de hacerse una obra tan importante, instruidos de sus derechos. El objeto de esta Sociedad será construir una gran plaza y los edificios que se jusguen convenientes, en el terreno que ocupaba el estinguido convento de San Francisco, y en el que hoy ocupa el de San Buenaventura, con arreglo a los planos que estan presentados á el gobierno. Esta sociedad se denominará del modo siguiente= Asociacion para construir la nueva Plaza de Sevilla: un teatro comico y demas edificios que se consideren de utilidad. La Sociedad se obliga á satisfacer el canon anual de tres por ciento sobre el valor de los edificios que se le conseden por el gobierno, y el citado censo de quince reales veinte y ocho maravedís en cada un año que sobre los mismos gravita desde el dia en que se le otorgue la escritura de dacion á censo, ofreciendo hipotecas [...] sin perjuicio de que respondan á mayor abundamiento como hipoteca natural los edificios que se construyan todo con arreglo á la citada real orden. Los edificios de propiedad particular que se indican en el referido plano presentado al Gobierno seran comprados por la sociedad por medio de un contrato privado, si es posible, y si no conforme á las condiciones prescriptas por la ley de expropiacion, previo el permiso del gobierno y autoridades competentes. Sin embargo aun en este caso insperado la Sociedad cuidará de que á los propietarios se guarden las consideraciones compatibles con la realizacion de su plan y pondrá todo su conato en las indemnizaciones equivalgan en un todo á las fincas que han de ser demolidas, y en que á nadie ceuste desarones ni lagrimas un proyecto dirijido especialmente al bien publico».

67 Saravia / Parreño, AHPS, legajo 1978, fol. 599, Sevilla, 1836: «[...] y dijeron que el Don Fernando sacó en subhasta y remate de la Real Hacienda de Su Majestad la renta llamada de Palmete, por todo el presente año de la fecha, que empezó a correr en el día primero de Enero hasta fin de Diciembre de el mismo, en la cantidad de sesenta mil reales Vellón, con la qualidad de dar fianzas hipotecarias; y que haviendo berificado dicha Subhasta no solo para sino tambien para el Don José Saravia con el fin de los dos hubiesen de percivir y pagar por mitad igualmente las utilidades o perdidas que produjese asi como este ha de hipotecar fincas suficientes que garanticen a dicha Real Hacienda de la mitad de la insinuada renta; han determinado oportuna Escriptura de Compañía y para que se verifique como corresponde».

68 Barea / Escacena, AHPS, legajo 3827, fol. 155-160, Sevilla, 1817: «Que el segundo ha hecho una contrata con la Real Fundicion de Artilleria de esta ciuda de escamondar los Pinos de las Dehesas de la misma Fundicion, nombradas Cañada honda, La Nueba, Las trecientas, y charena, cuyas quatro dehesas se hayan situadas en el termino de la villa de Aznalcazar, bajo ciertas clausulas, y condiciones que constan de la contrata que tiene firmada por tres años con la Junta de Artilleria [...] por razon de no tener fondos oportunos para ello, y tambien por no tener el tiempo oportuno para su continua asistencia en las citadas Dehesas, para observar, y cuidar de las operaciones del Escamondo, y teniendo su confianza del D. Mateo Barea, se ha combenido y conformado entre ambos en establecer compañía». 
/ Lara, donde el socio José Carmona «lleva en arrendamiento un corralón» que sirve para el reñidero de los gallos, obligándose los cinco socios a pagar el alquiler, incluido el socio que aporta el contrato ${ }^{6}$.

Si hasta aquí hemos podido observar la existencia de medios que facilitaban y llenaban de contenido el objeto del contrato de sociedad, a continuación analizamos los contratos que establecen una fianza o garantía; un aspecto de especial importancia para conferir a la empresa una estabilidad económica que asegurase el cumplimiento de las obligaciones contraídas. Estos contratos no revisten carácter excepcional en la práctica estudiada, como lo demuestra, entre otros, la cancelación de la compañía De Torres / Sánchez / Medel, donde los dos socios industriales, además, de asumir la general obligación personal de bienes y rentas también procedieron a aportar en garantía «tres aranzadas de olivar» por parte de Rafael Medel y «un pedazo de tierra calma» por parte de Francisco Sánchez ${ }^{70}$. Más original parece la pretendida sociedad anónima El Betis, que en vez de limitar su responsabilidad, como sería lógico, a los caudales desembolsados por los socios, constituyen a un tercero en fiador del arrendamiento del local donde se desarrolla el negocio ${ }^{71}$.

69 Carmona / Higuera / Casado / López / Lara, AHPS, legajo 8832, fol. 662, Sevilla, 1846: «Que el D. José Carmona lleva en arrendamiento un corralon de la propiedad de la Junta de Beneficiencia en esta ciudad en ella al sitio de la calle del Espejo junto a la Parroquia de San Román de esta dicha ciudad, el cual lo tiene destinado para reñidero de gallos y habiendo determinado celebrar compañía sobre las utilidades que pueda producir el indicado reñidero de Gallos á fin de que conste por instrumento publico en el presente por el cual instruido de su derecho $[\ldots] 4^{\text {a }}$. Que si durante los cuatro años que habrá de durar dicha compañía falleciere algunos de los otorgantes quedan obligados los demas á seguir en sociedad con sus herederos en el caso á estos les acomodora. $5^{\mathrm{a}}$. Que mediante á que la renta de dicha Corral consiste en quinientos reales cada año todos obligados a satisfaccerla por quintas partes iguales, la cual percibirá el Carmona anticipadamente respecto á que él es responsable á su pago al propietario de su finca».

70 Cancelación de la compañía De Torres / Sánchez / Medel, AHPS, legajo 1981, fol. 138, Sevilla, 1825: «Que por escriptura por otorgamos ante el año de mil ochocientos veinte y tres, por la sentamos aparceria por terceras partes de perdidas y ganancias en el trafico y negociación, de comprar y vender ganados de todas clases para el Matadero de esta ciudad, la qual sentamos por el termino de un año que empezó a contarse en primero de Abril de el dicho año de mil ochocientos veinte y tres; Cuya compañía duró hasta el año de mil ochocientos veinte y cinco en que terminó de acuerdo de nos todos tres: para qual puso yo el Torres por fondo quince mil Reales de Vellón y nos Sanchez y Medel solo nuestro trabajo e industria [...] que para la seguridad de las cantidades que entraren en poder de los dichos Sanchez y Medel ademas de las obligacion general de bienes y rentas habian de obligar como con efecto obligaron el Don Rafael Medel tres aranzadas de Olivar que le pertencian en termino de la Villa de Cantillana al sitio de Valde Infierno; y el Francisco Sanchez un pedazo de tierra calma termino de las misma Villa en la Vega de Vidal [...] para no poder las venderlas hasta estar reintegrado al Geronimo de Torres de todas las cantidades que tubiese desembolsadas, y chancelada dicha compañía, que asi con mas expresion aparece de la citada Escriptura».

71 E1 Betis (Fabrica anónima de Lienzos), AHPS, legajo 6595, fol. 780, Sevilla, 1845: «Los señores González y Mora, D. Miguel de San Juan Yñiguez y D. Vicente Martínez vecinos de esta Ciudad juntos de mancomun y dijeron se han propuesto asociarse y establecer una fabrica anónima de lienzos de las clases que mas conbenga fabricar de cuatro años bajo de las bases y condiciones siguientes. $1^{\mathrm{a}}$. El capital de que ha de constar la sociedad de ciento veinte mil reales de vellón en estos términos, cuarenta mil los Señores Gonzalez y Mora; cuarenta mil Don Miguel San Juan Yñiguez; y cuarenta mil D. Vicente Martínez bien sea en hilazas o enseres propios para la Fabrica ó bien en efectivo metalico siempre a conformidad de los tres socios. [...] $5^{\mathrm{a}}$. Como esta Sociedad se forma por cuatro años, y el arrendamiento de la casa Fabrica se ha hecho por cinco se constituyen los tres socios en la obligacion de pagar á prorrata el alquiler de dicha Casa en el ultimo año en el caso de que se convinieren á algunos de los socios continuar en ella pues dado este caso será de su sola cuenta toda vez que al concluir este contrato no las conbenga renovarlo por mas tiempo [...].6 Habiendose constituido fiador de D. Vicente D. Juan José Garcia Vinuesa de este Comercio y Vecindad se obligan los tres socios a responderle siempre y abonarle las cantidades que con documentos justificativos acredite haber tenido que entregan por efecto de la responsabilidad que por los socios ha contraído». 
Pero la mencionada estabilidad económica perseguida través de garantías y contratos o remates de subastas no agota la cuestión relativa a los fondos patrimoniales, toda vez que las escrituras expresan una pluralidad de situaciones que benefician el desarrollo del objeto social. Un ejemplo apreciamos en Echalan / de Peralta / Ynurria, una compañía en la que las diferentes estipulaciones establecen una cuenta paralela, ajena a la propia contabilidad y a los recursos financieros de la sociedad, para que la socia Rita Echalan proceda a la reparación de la fábrica de sebo y la «reposición de los utensilios» mediante los «fondos franqueados» por el consocio, Francisco Javier de Peralta ${ }^{22}$. Otro supuesto relacionado con el anterior es aquél en el que los socios se obligan a aportar unas sumas pecuniarias a favor de la sociedad, sin percibir contraprestación alguna, pero la compañía consigue así fortalecer su capacidad negociadora y proseguir la actividad comercial. En la sociedad Keyser / de Campos, uno de los socios, Francisco de Keyser, se ofrece a aportar los «fondos de mercaderías y géneros que tuviere por conveniente», pero sin ser obligado a «cantidad alguna determinada» ${ }^{73}$.

72 Echalan / de Peralta / Ynurria, AHPS, legajo 1953, fol. 666-671, Sevilla, 1824: «Lo decimo; hallándose las que actualmente existen en absoluta necesidad de reparación; y siendo necesario para ésto, y para la ampliación de ellas, en que hemos combenido, hacer una obra en la Finca, y sitios donde se hallen establecidas; y Careciendo la expresada Doña Rita, de los fondos necesarios para hacerla; hallándose el Don Francisco Javier de Peralta, pronto a franquearlos por hacerle merced, y buena obra, Declaramos por este Documento, que siendo estas Cantidades independientes de la negociación, dará la Doña Rita los oportunos recibos de las que bayan percibiendo con este objeto expresandolo asi, las quales se le cargarán en su Cuenta Corriente particular como se explicará en el Capítulo siguiente. Lo undecimo; Que por consecuencia del contexto del Capitulo precedente, el Don Francisco Javier, llevará una Cuenta Corriente particular con la Doña Rita Echalan, en la que le cargaría las partidas que el franquee en efectivo para la obra de las Cassas en que existen las Fabricas de esta Compañía, como las que le facilite con quales quisiera otro respecto, y pueda necesitar para la reposición de utensilios de su Cargo en las mismas Fabricas de Jabón y Sebo, assí como se le cargará igualmente la Cantidad de veinte y un mil Reales de Vellón importe de dos Letras de Cambio que la Doña Rita tiene Aceptadas, a la orden del repetido Don Francisco a dos diferentes fechas, cuia cantidad percibió la misma, con anterioridad, a nuestros Contratos: Estamos Combenidos en que las cantidades antedichas se bayan descontando de las utilidades que a favor de lo susodicho correspondan en esta Compañía. Mas sino las hubiere queda responsable a satisfaccerla con sus propias bienes, por ser independientes como queda explicados; Con Prebención que por cuanto con fecha el treinta y uno de Enero del año proximo passado de mil ochocientos veinte y tres haviamos celebrado Contrata también también de Compañía, solo en la Fabrica de Jabón, mediante este nuevo contrato la chancelamos, anulamos y damos por de ningun valor sin efecto, para que no tenga fuerza ni eficacia alguna ahora ni en ningun tiempo».

73 Lógicamente esta modalidad presenta características comunes con el aumento del capital social estudiado anteriormente. Compañía de Keyser / de Campos, AHPS, legajo 6460, fol. 211-214, Sevilla, 1761: «que por hazer buena obra, beneficio y merced a mi el dicho D. Domingo, y para que yo pueda subvenir á las precisas obligaciones de la manutencion, y alimentos de mi Cassa, y Familia el referido D. Francisco â determinado de su propio Caudal el poner tienda de Paños, y Lenzerias en esta dicha Ciudad en unas Cassas [...]. Primeramente que el fondo que yo el dicho D. Francisco pongo en la mencionada tienda son cinquenta y seis mill quinientos cinquenta y quatro Reales, y treinta maravedies de Vellon los setecientos, y cinquenta deellos en que se apreció el Mostrador, Estantes, Bancos, y demas peltrechos precisos, y correspondientes â la nominada tienda cinco mill, veinte, y dos Reales, y treinta maravedies, los mismos en que se apreciaron por Ynteligentes los generos que quedaron del dicho Don Augustin Alvarez, que por estar todo bien y por tener yo el dicho D. Domingo todo lo que va explicado me doy por entregado â mi voluntad sobre que renuncio las Leyes del entrego prueba del recibo y los cinquenta mill settencientos ochenta y dos R.v de fondo restante q importan las Ditas, q ay q cobrar de distintas Deudares del referido D. Augustin, las que yo el nomiando D. Domingo de Campos me obligo a cobrarlas mientras estuviere en el manejo de la dicha tienda en la conformidad que las deben pagar los citados deudores y siempre que me separe del manejo de ella ê de ser en dicha cobranza sin que por el trabajo que tenga en ello pueda tomar ni cargar para ni otra persona en cuenta Cantidad, ni cosa alguna, y mediante â que yo el enunciado D. Francisco de Keyser, soy sindico Depositario de los bienes, y efectos de la Quiebra del expresado D. Augustin Alvarez, me obligo â satisfacer, y abonar â los Acreedores de este el monto de las dos partidas pri- 
En Señores Calzada y Munilla se produce una difícil distinción entre el capital social en sentido estricto y los fondos patrimoniales anexos a la sociedad, debido a que parte del acervo incluye, por una parte, la fábrica propiedad de ambos socios con un tercero, Constantino de Stoops, resultando de extrema complejidad el deslinde de la propiedad de cada uno de los comuneros, y en segundo lugar, el concepto en que son entregados los bienes, procedentes de herencias de sus «respectivos padres, cartas dotales de esposas, bienes heredados por estas y adquiridos por cada uno durante sus vidas $\gg^{74}$.

Por último, ha de señalarse la posible incorporación de un contrato rubricado antes de la constitución de la sociedad, pero realizado de forma exclusiva por uno de los socios que, sin embargo, decide motu proprio conceder una parte del lucro al compañero, con el objeto de probar la buena fe que persigue en la nueva compañía ${ }^{75}$.

meras del Mostrador, Estantes, y Generos, y mas, lo que el dicho Don Domingo fuere cobrando efectivamente de las referidas Ditas, por quanto lo que no pudiere percivir, y cobrar por ser fallidas deben quedar, y quedan de quenta y cargo de los mencionados Acreedores y no de la mia [...] que yo el dicho D. Francisco de Keyser pondre [...] los demas fondos de Mercaderias, y Generos que tuviere por conveniente para el surtimiento deella, y su mejor manejo, despacho sin quedar obligado a cantidad alguna determinada».

74 Señores Calzada y Munilla, $A H P S$, legajo 875, fol. 1271-1274, Sevilla, $1844:$ « $1^{\circ}$ El D. José de la Calzada tiene hoy de capital en giro, en creditos y varios efectos la cantidad de reales vellon un millon doscientos noventa y dos mil cincuenta y ocho y diez y ocho maravedís y el D. Manuel Maria Munilla la de quinientos ochenta y un mil seiscientos setenta y nueve reales vellon. $2^{\circ}$ Ambos socios se garantisan mutuamente dichos capitales por haver hecho los valances e inventarios correspondientes desde diez y ocho de Febrero de este año desde cuyo dia debe tenerse por formada esta sociedad por manera que las ganancias o perdidas que hubiere habido desde aquella fecha seran pertibles entre ellos del modo y forma que despues se espresará. [...] $7^{\circ}$ Declaran: que son y componen parte de dichos capítales la Fabrica que en union con D. Constantino de Stoops tienen establecida en esta Ciudad plaza de San Blas numero veinte y nueve Collacion de Santa Marina según la tienen constituida por ante mi el Yntrascripto Escribano Publico en siete de Setiembre de mil ochocientos cuarenta y uno. [...] $12^{\circ}$ Ambos socios declaran que el capital que importan en la Sociedad proviene de los bienes heredados de sus respectivos padres, cartas dotales de mis esposas, bienes heredados por estas y adquiridos por cada uno durante sus vidas. Las Cartas dotales y herencias constan de los respectivos documentos, y los adquiridos por los valances practicados antes del citado Febrero y que ambos reconocen y declaran ya inutiles para que en adelante solo sirvan las cantidades señaladas en esta Escritura pues toda otra cuenta anterior así mismo la declaran nula y de ningun valor». Por otra parte, Manuel Morales Muñoz, «El papel de las élites en la industrialización andaluza», en Baetica. Estudios de Arte, Geografia e Historia, (1999), n ${ }^{\circ}$ 21, pp. 431-449, expone la existencia de una sociedad intitulada Calzado Munilla y Destorn que pudiera ser la referida en la escritura analizada y que contó con una máquina de vapor y ocupaba más de 300 personas, una cifra nada desdeñable para la época.

75 Steinacher y Compañía, AHPS, legajo 8832, fol. 671-680, Sevilla, 1846: «D. Gustavo Steinacher ingeniero civil frances antiguo arquitecto municipal en gefe de la administracion municipal de Paris, Francia, y D. Pablo Rohault de Fleuri antiguo discipulo de la escuela de minas, tambien ingeniero civil frances y residente de esta ciudad en el dormitorio de San Pablo hoy Calle de Baylen [...] que habian convenido reunirse en sociedad en tanto para llebar a cabo las empresas y negociones que el D. Gustavo tiene pendiente en esta ciudad y fuera de ella como para cuentas especulaciones y empresas publicas ó privadas puedan proporcionarseles en el sucesivo y á fin de que conste por instrumento publico es el presente por el cual instruidos [...]. $5^{\mathrm{a}}$ Todos los negocios ó empresas hechos ó ejecutados por uno de los socios quedarán por cuenta de la compañía siendole formalmente prohivido el hacer en España ningun negocio, empresa ó especulacion por su cuenta ó utilidad particular á no ser con el consentimiento anticipado dado por escrito por su consocio. En este caso el asociado que obre por su cuenta particular con la autorización previa de su compañero estará solo él obligado bajo toda la responsabilidad á que haya lugar en derecho al cumplimiento esacto de los contratos que celebre con el fin de que en ningun tiempo ni circunstancia pueda ser molestada ni reconvenida la sociedad, lo cual asi se expresará en los contratos y mercados que haga ó convenga y á las personas quienos contraiga, para que en todo tiempo conste obra esclusivamente por su cuenta particular. $9^{a}$ Los bienes de esta sociedad se componen del liquido producto que resulte de la antigua sociedad llevada entre el D. Gustavo Steinacher y D. Fernando Bernadet disuelta ante mi en quince de este mes, y de las utilidades liquidas de las varias empresas pendientes de la misma Sociedad disuelta y todo lo llevado á ella esclusivamente por el D. Gustavo Steinacher. 10ª El D. Gustavo Steinacher para 


\section{El momento de formación del capital social: el incumplimiento del socio}

Los textos legales y la doctrina se preocupan por analizar y regular en qué momento se constituye de forma efectiva el fondo de la compañía y los efectos que trae aparejado el eventual incumplimiento de la obligación del socio de aportar su parte de capital social. Una situación lógica, si tenemos en cuenta su incidencia en la responsabilidad patrimonial de los socios y de la compañía, así como en los diferentes derechos de los compañeros, como los beneficios que pudieran obtener ${ }^{76}$.

Las ordenanzas y los proyectos previos al Código se interesan por esta cuestión y normativizan los efectos en el incumplimiento de la obligación de entregar los efectos al caudal común. Brilla, a este respecto, por su extensión el proyecto de ordenanzas gaditano, que aborda con pulcritud esta cuestión tan importante para la sociedad y para la asunción de las obligaciones contraídas. El citado proyecto obliga, obviamente, a efectuar el desembolso de los fondos prometidos ${ }^{77}$, pero también caben otras hipótesis que pueden producirse en la constitución del capital. Es el caso del director de la compañía que «disimulara» la verdadera entrega del bien, asumiendo en exclusiva la responsabilidad de tal acción y manteniéndose la compañía al margen de perjuicio alguno ${ }^{78}$. Asimismo, también priva de las utilidades al socio que no realizó oportunamente el desembolso correspondiente a su parte de capital y le obliga al abono de los gastos realizados por los compañeros a causa de las diligencias para exigir el pago de su porción de capital ${ }^{79}$; en el hipotético caso de que el requerimiento fuera judicial y el socio constituido en mora no hubiera realizado la

dar una prueva evidente al D. Pablo Rohault de Fleury de sincera y cordial a mitad le cede un diez por ciento de las uitilidades liquidas deducidas los gastos y carga de cualquier naturaleza que sean de la construccion del nuevo puente de hierro de estar Ciudad a pesar de separarse en la citada escritura de disoluciond de sociedad el D. Pablo Rohault de la participacion que tubiere en su obra, quedando subsistente en lo demas el articulo septimo de dicha escritura con la reserva que en ella hace el repetido Rohault con respecto a lo que pueda corresponderle por la contruccion del nuevo teatro en esta ciudad y la conduccion de agua á Jerez de la Frontera y en vista de la consesion que gratuitamente le hace el D. Gustavo de las utilidades que produzca la citada obra del puente se obliga como prueba de reconocimiento á prestar con sus luces y esperiencia los servicios que esten á mis alcances á conseguir el escrito favorable de la repetida empresa del puente de esta Ciudad sea cual fuere su obligacion y hasta su entrega a gobierno. $11^{\text {a }}$ Esceptuando la empresa el puente de esta ciudad, la contruccion del nuevo teatro y la conduccion de aguas á Jerez de la frontera todas las utilidades que resulten de todas las negociaciones emprendidas ó que en lo sucesivo se emprendan en virtud de este contrato seran partibles por iguales porciones entre los dos otorgantes. Las perdidas que resulten en cada operación seran llevadas en la misma proporcion. [... $21^{\text {a }}$ A escepcion de los papeles de familia y de interes privados perteneciente a los herederos fallecido todos sus demas papeles planos, cuentas por menor y demas documentos concernientes á sus estudios facultades quedarán de la esclusiva propiedad de la compañía».

76 En este sentido, Martínez Gijón, Historia del derecho mercantil, p. 434. Sobre la responsabilidad patrimonial de los socios en Sevilla en los siglos XVIII y XIX, Jesús Jimeno Borrero, «Compañía mercantil en Sevilla: condición de socio (siglos XVIII-XIX)», en Legal History Review, en prensa.

77 Proyecto de Ordenanzas del Real Tribunal del Consulado de Cádiz 1800, trat. 4, tít. 2, ley 21: «Los fondos de cada compañero deberán realmente ponerse en poder del que lleve la dirección y los Libros, asegurándose en una Caja á su cuidado, y responsabilidad, ô con intervención de otro, dos, ô mas llaves según se pactare».

78 Proyecto de Ordenanzas del Real Tribunal del Consulado de Cádiz 1800, trat. 4, tít. 2, ley 31: «Si habiéndose nombrado Director con encargo de los fondos de los socios disimulare á alguno el verdadero en poner su parte, ô le admitiere créditos, ô efectos quedará solo responsable de modo que á la compañía no se siga perjuicio alguno

79 Proyecto de Ordenanzas del Real Tribunal del Consulado de Cádiz 1800, trat. 4, tít. 2, ley 32: «Ynterin el compañero no hace real entrega del capital que le toca, no tendrá acción â utilidad alguna»; ley 35: «Pasado el termino que se hubiere designado, ó el señalado para en defecto de esto, podrá y deberá requerirle la compañía cuyos socios serán responsables de aquella cuota por la emisión de las diligencias oportunas para el cobro». 
entrega transcurridos tres días, los restantes socios tienen derecho a excluirlo de la compañía ${ }^{80}$.

El Código y la doctrina posterior se cuestionan sobre el momento en el qué ha de realizarse la entrega del capital. Pardessus reconoce una doble limitación para llevar a efecto la entrega de los efectos en el fondo de la sociedad; en primer lugar, el momento del otorgamiento $\mathrm{y}$, en segundo lugar, el tiempo en que haya sido establecido en el contrato de sociedad ${ }^{81}$. El autor francés parte de la voluntad de las partes manifestada en una disposición específica de la escritura y subsidiariamente propone considerar la naturaleza de las cosas prometidas ${ }^{82}$. Aunque otras voces de la doctrina española, como Martí de Eixalá, se remiten a la voluntad de las partes manifestada en el contrato; de no haberse señalado, se sigue la fecha fijada posteriormente en la «caja de la sociedad» ${ }^{83}$.

El Código de Comercio de 1829 parte de dos incumplimientos por parte de los socios para hacer el depósito o entrega de los bienes al capital social. Estos incumplimientos, a pesar de la errónea terminología utilizada por el Código, puede interpretarse como un primer supuesto, el incumplimiento total por el socio de la cuantía a entregar, otorgando a la sociedad mercantil la posibilidad de elegir entre la ejecución de los bienes del socio díscolo o la rescisión del contrato en lo que respecta al «socio omiso ${ }^{84}$. Muy interesante resulta, en este punto, la tesis sostenida por González Huebra sobre si, ante la negativa de la sociedad a ejercitar cualquiera de los derechos señalados frente al socio moroso, pudieran los acreedores de la sociedad proceder contra él y obligarle a entregar la parte prometida. El autor, como Vicente y Caravantes $^{85}$, se manifiesta en sentido afirmativo, aunque considera que ningún acreedor

80 Proyecto de Ordenanzas del Real Tribunal del Consulado de Cádiz 1800, trat. 4, tít. 2, ley 37: «El socio requerido deberán entregar sus fondos desde tercer dia, y en lo contrario podrá ser excluido de la Compañía sobre todo el requerimiento fue judicial en la fase dicha».

81 No ha de olvidarse la primacía de la voluntad de las partes en el derecho mercantil tal como revela el propio código fernandino de 1829; Código de Comercio 1829, art. 299: «El régimen de las sociedades mercantiles se ajustará a los pactos convenidos en la escritura del contrato, y en cuanto por ella no se haya prescrito y determinado, a las disposiciones siguientes».

82 J. M. Pardessus, Cours de droit commerce, núm. 986, pp. 486-487.

83 Martí de Eixalá, Instituciones de derecho mercantil, pp. 268-269.

${ }^{84}$ Código de Comercio 1829, art. 300: «No cumpliendo algún socio con poner en la masa común en el plazo convenido la porcion de capital á que se hubiere empeñado en el contrato de sociedad, tiene la compañía opcion entre proceder ejecutivamente contra sus bienes para hacer efectiva la porción de capital que haya dejando de entregar, ó rescindir el contrato en cuanto á socio omiso, reteniendo los intereses que tenga en la masa social en la forma que se establece en el artículo 327». Sin embargo, ha de advertirse en esta materia la puntualización que efectúa González Huebra sobre ambas soluciones jurídicas, toda vez que dicha responsabilidad ha de concurrir al grueso de la compañía «por necesidad porque la exclusión de un socio altera las bases de la escritura y disminuye el capital social si los demás no se comprometen a suplir la parte del excluido», Curso del derecho mercantil, p. 200. La redacción de este artículo viene precedida del conocimiento de Pedro Sainz de Andino del Proyecto de Ordenanzas del Consulado de Málaga que se proyecta en el mismo sentido, aunque prevea dos elementos novedosos respecto de las novedades que introduce posteriormente el autor gaditano. Primero, atribuye a los socios la potestad de rescindir el contrato de sociedad frente al socio deudor en conjunta forma a la posibilidad de exigirle daños y perjuicios, y segundo, en el hipotético supuesto de que la sociedad entrara en quiebra, ésta se cargará contra los socios que debiendo haber aportado la cantidad correspondiente no la hubieran completado. Proyecto de Ordenanzas del Consulado de Málaga 1828, art. 480: «Todo socio aprontará el capital que estipuló íntegramente y dentro del término señalado en la escritura. Su omisión autoriza a los consocios para pedir se rescinda el contrato. También pueden reclamar daños y perjuicios. En caso de quiebra se hará cargo a los socios que no hayan obligado a completar la parte del capital estipulado».

85 Aunque ambos autores se expresan en sentido positivo, ha de matizarse que Vicente y Caravantes, a diferencia 
puede tener los derechos contra los socios en particular, ni contra los deudores de la misma $^{86}$. Lógicamente, resulta imposible conocer, a través de las fuentes consultadas, si fue usual la ejecución de los bienes del compañero deudor por parte de los socios en materia judicial. Sin embargo, aunque la práctica sevillana no ofrece generalmente los motivos de las separaciones prematuras de las compañías ${ }^{87}$, encontramos excepcionalmente dos sociedades que reproducen la segunda solución prevista en el Código. Se trata de la «Asociación para la construcción de la Plaza Nueva de Sevilla» donde algunos de los socios (J. Álvarez y Benito y J. Pareja y Barona) son apartados de la misma por no hacer efectiva la suma acordada en el momento establecido para ello en el contrato de sociedad ${ }^{88}$.

de Pablo González Huebra, funda su posición sobre la base de que los acreedores pueden demandar al moroso ejercitando los distintos derechos de los gestores, Vicente y Caravantes, Código de Comercio, pp. 109-110.

86 González Huebra, Curso de derecho mercantil, p. 200.

87 Sobra con observar las escrituras siguientes que no especifican las razones del disenso entre los socios: Distrato de la compañía Sánchez / García, AHPS, legajo 2920, fol. 329, Sevilla, 1804: «Otorgaron compª de tienda, taberna y media fonda que yo el Juan Sanchez intentaba poner en el citado Barrio entrando en fondo cada uno siete mill reales de vellón que yo el dicho Juan Sanchez recibí del Miguel Garcia [...]. Y haviendo ocurrido motibos que ynpiden la continuacion de dicha compañía hemos combenido, los dos otorgantes en desaserla [...] Y por que el Juan Sanchez ha restituido â mi el Miguel Garcia los siete mil Reales de vellón que se entregue quando hicimos el combenio, y de que en la relacionada escriptura, me otorgo Carta de Pago, y yo los he recibido en contado á mi entera satisfacción». También en la separación de la compañía De la Cerda / Sánchez, AHPS, legajo 1952, fol. 65, Sevilla, 1823: «A mitad de perdidas y ganancias en el trafico y negociación de comercio de dos tiendas de merceria y Quincallas y Lencerias que teniamos establecida en la citada Villa de Fregenal de la Sierra por tiempo de cuatro años y bajo las condiciones. A la que hicimos otra Agregación en nueve de Junio del citado año de mil ochocientos veinte y uno, con varias advertencias, como de ambas consta aquí nos remitimos. Y aunque no está vencido el plazo de establecimiento que por ciertas circunstancias que han incidido hemos convenido en disolverla para lo que se ha liquidado la cuenta general y por ella resultando a favor de el Don Mariano cierta cantidad despues de haverse hecho cargo de la Dependencia hemos combenido disolver y chancelar aquella sociedad y Contrato; y desde luego ambos de comun acuerdo en la via y forma que haya lugar en derecho. Otorgamos que disolvemos dicha Compañía, y rescindimos aquel contrato, y Chancelamos, anulamos y damos por ningun efecto la relacionada escriptura de dicho establecimiento para que no valga ni haga fe en Juicio ni fuera de el, como cosa fenecida pasada y cumplida y consentimos que su razón se anote en esta Matriz, en las Copias que se hallan dado, y donde mas combengan para que siempre conste; Y porque el Don José de la Cerda estaba hecho cargo de la Dependencia, y que ha liquidado la cuenta entre ambos hasta este dia, y Cargas resultas ha celebrado este a favor de mi el Don Mariano la competente escritura de obligacion cierta cantidad en este dia de la fecha ante el presente Escribano Publico desde luego lo relevo al Don José de las responsabilidades que tenia y hasta el presente, como de lo que pueda resultarle en lo sucesivo por aquel establecimiento y dependencia que tubimos en Compañía para no quedar obligado a su resultado en modo alguno. Y ambos nos obligamos a haver por firme lo expresado en todo tiempo con nuestros bienes y rentas presentes y futuras»».

88 Convenio y Separación de socios de la Asociación para la construcción de una Plaza Nueva de Sevilla, AHPS, legajo 882, fol. 87-88, Sevilla, 1846: «D. Manuel del Castillo, Don Juan Murphi, D. Angel de Ayala, y Don Juan Pareja y Barona, don Francisco López Roda y Don Narsiso Bonaplata, Don Domingo de Ayala y José Alvarez y Benito, vecinos de esta Ciudad dijeron que en veinte y dos de Enero de mil ochocientos cuarenta y tres en el registro de la presente Escribania, y por ante el Don Miguel Gonzalez. Otorgaron escritura por la que formaron cierta sociedad para construir uan gran plaza y los edificios que se juzgaren convenientes en el terreno que ocupaba el estinguido convento de San Francisco de esta ciudad y en el que hoy ocupa el de San Buenaventura con arreglo á los planos que estaban presentados al gobierno y bajo las diferentes condiciones. Que continuando sus reuniones y solicitudes para llevar a cabo tan interesante empresa han convenido ciertos socios de acuerdo con los demás en aprontar cierta cantidad poniéndola a disposición del Don Narciso Bonaplata para dar principio á la realización del proyecto, y otros no acomodándoles continuar en la sociedad han determinado separándose de ella, y para que todo conste como es debido instruido de su derecho Otorgan que los socios Don Narciso Bonaplata Don Angel de Ayala, Don Manuel del Castillo Don Juan Murphi y Don Francisco Lopez Rodas, se obligan á aprontar la cantidad de diez mil reales vellón por partes iguales en efecivo metalico con esclusion de todo papel, la cual desde luego tienen á disposición del Don Narciso Bonaplata para entregarla cuando la pedida 
Una circunstancia similar se produce en la sociedad constituida por el Dr. Fermín de la Puente y Apecechea en la que solo queda constancia de sumas adelantadas por la Viuda de Bartelemy, pero cuyo capital no ha sido enteramente desembolsado, resolviéndose el contrato de sociedad respecto a ella y asumiendo en exclusiva el Dr. Fermín de la Puente y Apecechea los derechos y obligaciones de la compañía, incluida la devolución de las cantidades adelantadas por la Viuda de Bertelemy ${ }^{89}$.

El segundo supuesto que contempla el código fernandino es el retraso de la entrega completa de la porción del fondo común, lo que faculta a la compañía a exigirle al socio deudor el «interés corriente del dinero que hubiere dejado de entregar a su debido tiempo ${{ }^{90}}^{\circ}$. Aunque resulta imposible conocer, con la documentación manejada, observando que esta cuestión fue objeto de reclamaciones judiciales, la reclamación de los intereses por los socios frente al compañero deudor. Sin embargo, se ha hallado en el corpus documental una escritura donde se estipula la obligación de abonar el $6 \%$ de interés por parte del socio «moroso» ${ }^{11}$.

con el objeto de que por mano de este se vaya destinado en los gastos necesarios según el fin de la sociedad y los trabajos que deben ejercitarse para llevar a cabo el proyecto pero si no entregare alguno de ellos la suma mencionada á los tres días de reclamarla el Don Narciso Bonaplata, y se dan por separado de ella absolutamente bastando dicha reclamación del Señor Bonaplata por todo requerimiento y los socios Don Jose Alvarez y Benito y don Juan Pareja y Barona, se separan y apartan de la empresa renunciando cualquier derecho que puedan haber adquirido y sin que tampoco se les pueda pedir cosa alguna, quedando chancelada en cuanto á ellos la repetida escritura de sociedad, apremiándoseles á su cumplimiento como ál pago de las costas, gastos y perjuicios que por su infracción se causaren en virtud de esta escritura y el pedimento jurado de la parte autora sin otra prueba aunque por derecho se requiera».

89 Disolución de Señores Viuda de Bartelemy y D. Fermin de la Puente y Apecechea, AHPS, legajo, 874, fol. 508513, Sevilla, 1843: «D. Juan de la Puente y Apecechea como apoderado de su hermano el Dr. D. Fermin de la Puente y Apecechea en virtud del que le confirió ante mi y D. Fermando Calvo Rubio por si y en nombre de $\mathrm{D}^{\mathrm{a}}$ Maria Josefa Garcia y Garcia, Viuda de Bartelemy vecina de la Ciudad de Cadiz y residente en esta, el Dr. D. Fermin de la Puente y Apecechea y D. Fermando Calvo Rubio que habiendo reasumido entre los dos primeros toda la representación de la Casa Borbolla, Linares y compañía de que fueron socios desde su creacion, en virtud de cesion que bajo diferentes conceptos han hecho en ellos, todos los demas consocios [...]. $2^{\circ}$ La Viuda de Bartelemy cede al D. Fermin de la Puente y Apecechea la participación completa que tiene en dicha sociedad, en el valor, precio y forma que han convenido; y en su consecuencia conformes en la liquidacion y fijacion de capitales, con entero conocimiento y de propia voluntad la Señora Viuda de Bertelemy ha recibido pagares que responden suficientemente del importe convenido de que otorga á favor del D. Fermin de la Puente y Apecechea la mejor y mas bastante carta de pago que le interese de quien nada reclamará por ningun motivo con relacion á esta sociedad mas que el esacto cumplimiento de los pagarés que quedan firmados; y el D. Fermin por su parte aceptar los derechos, obligaciones y entera representación que la Señora Viuda tiene en la sociedad. $3^{\circ} \operatorname{Los}$ adelantos de cantidades que por cualquier motivo hayan hecho, como socios capitalistas, la Señora Viuda de Bartelemy y D. Fermin de la Puente se consideran mutuamente compensados».

90 Código de Comercio 1829, art. 303: «Todo socio que por cualquiera causa retarde la entrega total de su capital mas allá del término que se hubiere prefijado en el contrato de sociedad, ó en el caso de no haberse prefijado, desde luego que se estableció la caja, deberá abonar á la masa comun el ínteres corriente del dinero que hubiere dejado de entregar á su debido tiempo».

91 Señores Viuda de Bartelemy y D. Fermin de la Puente y Apecechea (Borbolla, Linares y Compañía), AHPS, legajo 874, pp. 508-513, Sevilla, 1843: «4 El capital que se presupone para la nueva empresa será el de pesos fuertes veinte mil los cuales se obligan á contribuir por mitad teniéndolos a disposicion de la sociedad por una vez los referidos Señores Viuda de Bartelemy y D. Fermin de la Puente y Apecechea. De ellos entregan al fondo social y se hacen reciproco abono hasta la cantidad de doscientos veinte y ocho mil novecientos trece [...] la Señora Viuda e igual cantidad el D. Fermin de la Puente debiendo hacer las entregas posteriores en metalico por mitad y á medida que sean necesarias para las operaciones de la sociedad, en virtud de recibo otorgado por la sociedad á favor del que entregue y en que conste la conformidad del otro socio ó de quien su poder hubiere, cuyos recibos para formar la cuenta de division de ganancias y perdidas y calcular el interes que represente cada uno en el fondo social y existencias de la sociedad en caso de disolucion de la misma. $5^{\circ}$ Estas entregas se harán 
Por último, hemos de cuestionarnos si se conoció alguna posibilidad para admitir o permitir la omisión de la aportación del socio en el fondo común. Es la doctrina $\mathrm{y}$, en concreto, una de sus voces más autorizadas como J. M. Pardessus, quien se expresa en un sentido positivo, ya que admite la legítima excepción de fuerza mayor, especialmente cuando lo que ha de entregarse es un bien o $\operatorname{cosa}^{92}$. Por otra parte, la práctica sevillana examinada no ofrece ejemplos de la negativa de algún socio de conferir su parte del capital social en razón de alguna excepción de fuerza mayor, remitiéndose mayoritariamente las cláusulas de separación o disolución a cuestiones generales, sin especificar o concretar el motivo.

Una cuestión diversa es el momento en el que se entiende realizada la entrega de los créditos que poseía el socio y que cede a beneficio de la sociedad como parte del capital social. El Proyecto de Ordenanzas del Consulado de Málaga considera que se instituirá como fondo común en el instante en el que hayan sido realizados, quedando de cuenta del socio en el supuesto de que hubieran devenido incobrables ${ }^{93}$. En términos parecidos se expresa el proyecto gaditano"s.

El Código de Comercio no altera el tenor de los textos consulares que impone la obligación de aportar al caudal de la compañía aquellas cantidades entregadas mediante créditos y cubrir su porción de capital social ${ }^{95}$. Esta orientación es la que asume la doctrina española sin hacer variación alguna ${ }^{96}$. Pardessus recomienda que el compañero que entrega los derechos facilite los títulos, los transportes y los endosos necesarios para ejecutar los créditos entregados ${ }^{97}$.

\section{Conclusiones}

El presente artículo se interpreta como una primera aproximación al capital social desde una perspectiva histórica, una importante materia rodeada de aristas y cuestiones conexas como la titularidad de los bienes, atribuidos en razón de la personalidad jurídica a la propia sociedad, a partir de inicios del siglo XIX, o la problemática que se suscita con la determinación exacta del capital y el momento en el que se considera constituido, circunstancias de una importante naturaleza práctica, toda vez que afecta a la responsabilidad de los socios y de la propia sociedad.

en virtud de reclamacion de la direccion de la sociedad y en el termino de quince dias desde el en que fueren pedidas advirtiendo que caso de no verificarse dichas entregas dentro de dicho plazo se abonará al socio que esté en desembolso un interes de seis por ciento anual sobre la cantidad que haya anticipado, cuyo importe se cargará á la cuenta del moroso».

92 J. M. Pardessus, Cours de droit commerce, núm. 986, pp. 486-487.

93 Proyecto de Ordenanzas del Consulado del Málaga 1828, art. 481: «Los créditos que introduzca algún socio en la compañía no se consideran capital hasta después de realizados. Si no llegan a cobrarse se entienden siempre que están por cuenta del que los introdujo».

94 Proyecto de Ordenanzas del Real Tribunal del Consulado de Cádiz 1800, trat. 4, tít. 2, ley 29: «Aunque se hayan admitido los créditos, por parte de capital de su compañero, ni se contemplará que ha cumplido hasta realizar la cobranza, ni se le graduara por principal suyo el valor de los créditos».

95 Código de Comercio 1829, art. 302: «Entregando un socio á la compañía algunos créditos en descargo del capital que debiere poner en ella, no se le abonarán en cuenta hasta que se hayan cobrado; y si no fuesen efectivos, despues de hecha ejecucion en los bienes del deudor, ó si el socio no conviniere en hacerla, estará obligado á responder sin demora del importe de dichos créditos hasta cubrir la parte del capital de su empeño».

96 Sobre esta cuestión se expresan brevemente, Méndez y Balcarce, Instituciones y doctrinas, p. 26, y González Huebra, Curso de derecho mercantil, pp. 133-135.

97 J. M. Pardessus, Cours de droit commercial, núm. 986, pp. 486-487. 
Además, el trabajo, mediante su análisis documental, legislativo y doctrinal, ha buscado enriquecer los conocimientos mercantiles de Sevilla en un período fundamental de su historia como es el comprendido entre el final del Antiguo Régimen y la llegada del capitalismo. Dos etapas, que a priori, pueden suponer dos etapas distintas y una auténtica ruptura evolutiva en la forma de interpretar el contrato de sociedad. Aunque la realidad estudiada demuestra la continuidad de la compañía de tipo medieval caracterizada por algunos elementos; el objeto de comercio dedicado a una actividad comercial de reducido tamaño, como las tabernas o las labores agrícolas de limitada extensión, algún negocio artesanal en el que los socios y artífices son los propietarios de los útiles, como se aprecia en la compañía de Vicedo / Calero / Carrasco / Lerrezuelo / Merlo. Compañías que no requieren de una importante inversión, ni de grandes capitales que sostengan la actividad.

Este esquema se completa con la concurrencia de dos elementos corporativos: de una parte, la existencia de un socio que aporta un capital que, ante la expresa prohibición de la usura, encuentra en la compañía la forma óptima de vehicular una ganancia en la especulación, y de otra parte, el saber mercantil singularmente valorado, que se traduce en el reparto de las ganancias de la sociedad y en la materialización en la compañía sevillana de la regla de la affectio societatis y del consensus.

La naturaleza crematística del comercio y de la práctica societaria demuestra la despreocupación por complejas elaboraciones doctrinales a propósito de conceptualizar el capital social u otras materias que no revistan una singular finalidad práctica. Un ejemplo se aprecia en la inexistencia de sociedades que atribuyan la propiedad del bien a la compañía, aun cuando se hubiera iniciado la equiparación entre compañía y «ser moral comerciante»; la personalidad jurídica de la sociedad. Existiendo por el contrario, numerosos ejemplos de sociedad donde los socios, generalmente los capitalistas, se reservan los bienes aportados al capital social, como se pudo apreciar en la compañía de Ramón Torrijos.

Diferente es la importancia que muchas de las escrituras otorgan a la materia de la determinación del capital, tanto a los posibles aumentos del capital como a la detracción de sumas, y cuyo incumplimiento por parte de los socios lleva aparejada, en algunas ocasiones, la resolución unilateral del contrato de compañía, porque la retirada continúa o fraudulenta de fondos patrimoniales pueden suponer, no solo la inviabilidad de la actividad comercial, sino algo de mayor importancia en este momento histórico, la quiebra de la affectio societatis, de una confianza que obliga a los socios y compañeros a compartir el pan y el trabajo codo con codo.

Porque, más allá de la simple redacción de un código, han de tenerse en cuentas otras circunstancias que influyen en la práctica societaria como las circunstancias geográficas o socioeconómicas y la propia cultura mercantil de una sociedad básicamente iletrada, cuya voluntad se había ido plasmando desde antiguo en documentos de naturaleza privada.

\section{Fuentes}

- Archivo Histórico de Protocolos de Sevilla.

- Archivo de la Cámara de Comercio de Sevilla.

- Ordenanzas del Consulado de Bilbao de 1737 
- Borrador de Ordenanzas del Proyecto de Consulado «Nuestra Señora de la Inmaculada Concepción» 1764.

- Ordenanzas del Consulado Nuevo de Sevilla 1784.

- Proyecto de Ordenanzas del Real Tribunal del Consulado de Cádiz 1800.

- Proyecto de Ordenanzas del Consulado de Málaga 1828.

- Código de Comercio 1829

- Proyecto de Código de Comercio de 1837.

- Proyecto de Código de Comercio de 1838.

\section{Bibliografía}

Abásolo, Ezequiel, «El código de comercio español de 1829 en los debates y las prácticas jurídicas del extremo sur de América», en Anuario de Historia del derecho español, 7879, (2008-2009), pp. 447-460.

Álvarez Pantoja, María Luisa, Aspectos económicos de la Sevilla fernandina (1800-1833), Sevilla, Diputación Provincial, 1970.

«Capitales americanos en la Sevilla del S. XIX: el Marqués de Palomares del Río», en $A n$ dalucía y América en el siglo XIX: Actas de las V Jornadas de Andalucía y América, La Rábida, Universidad Internacional de Andalucía, (1985), pp. 349-370.

Amadori, Arrigo y Caamaño Dones, Josué, «Los «factores mercantiles» en el comercio indiano a través de la legislación y la literatura jurídica (siglos XVI-XVIII)», en Revista Complutense de Historia de América, vol. 32 (2006), pp. 85-101.

Ansón Peironcely, Rafael, La ley y el reglamento de 1848 sobre compañias mercantiles por acciones, Tesis doctoral dirigida por Juan Sánchez-Calero Guilarte, Universidad Complutense, Madrid, 2015.

Ascarelli, Tulio, Iniciación al estudio del derecho mercantil, Bosch, Barcelona, 1964.

Avecilla, Pablo de, Diccionario de la Legislación Mercantil, Madrid, Imprenta de D. Severiano Omaña, 1849.

Bacardí, Alejandro de, Tratado de Derecho Mercantil de España, Barcelona, Imprenta de D. Benito Espona, 1840.

Barrientos Grandón, Javier, Historia del Código de Comercio de la República de Chile. Sobre la cultura a través de un libro, Santiago de Chile, Pontificia Universidad Católica de Chile, 2015.

Bernal, Antonio Miguel y García Baquero-González, Antonio, Tres siglos de comercio sevillano (1598-1868), Sevilla, Universidad-Fundación Cámara de Comercio de Sevilla, 2011.

Calvo Vidal, Isidoro Antonio, La persona jurídica societaria, Madrid, Consejo General del Notariado, 2011.

Caroni, Pio, Escritos sobre la codificación, Madrid, Dyckinson-Universidad Carlos III de Madrid, 2012.

Carrasco González, María Guadalupe, Los instrumentos del comercio colonial en el Cádiz del siglo XVII (1650-1700), Banco de España-Estudios de Historia Económica, $\mathrm{n}^{\mathrm{o}} 35$, 1996.

Castro y Bravo, Federico de, Derecho civil de España, t. II, Pamplona, Aranzadi, 2008.

Daguerre, Pedro Antonio de, Alfabeto del Código de Comercio, Madrid, Imprenta de la Viuda de Villalpando, 1830. 
Foyer, Jean, Jean Foyer, «Sens et portée de la personnalité morale des sociétés en droit francais», en S. Bastid; R. David; U. Drobnig; L. Focsaneanu; J. Foyer; J. Grossen, La personnalité morale et ses limites. Études de droit comparé et de droit international public, Libraire Générale de Droit et de Jurisprudence, París, 1960.

Franch Benavente, Ricardo, Crecimiento económico y enriquecimiento burgués en la Valencia del siglo XVIII, Alfons el Magnanim, Valencia, 1986.

García Sanz, Arturo, «Las sociedades mercantiles en el Código de Comercio de 1829», en M. A. Chamocho Cantudo, Jorge Lozano Miralles (eds.), Sobre un hito jurídico de la constitución de 1812, Jaén, Universidad de Jaén, 2012

García Ulecia, Alberto, «Las condiciones de licitud de la compañía mercantil en Castilla bajo el derecho común», en Historia, Instituciones, Documentos, 7, (1980), pp. 39-94.

«Naturaleza y extranjería en las Corredurías de lonja del Antiguo Régimen», en Anuario de Historia del Derecho Español, 61 (1991), pp. 87-110.

García-Baquero González, Antonio, Cádiz y el Atlántico, Sevilla, Publicaciones de la Escuela de Estudios Hispano-Americanos de Sevilla-Universidad de Sevilla, 1976.

García-Baquero González, Antonio y Álvarez Santaló, León Carlos, «Funcionalidad del capital andaluz en vísperas de la primera industrialización» en Revista de estudios regionales, 5 (1980), pp. 101-134.

Girón Tena, José, Las sociedades mercantiles en el Código de Comercio. En Centenario del Código de Comercio, Madrid, Ministerio de Justicia, 1986, pp. 170-209.

Gómez Rivero, Ricardo y Palomeque López, Manuel Carlos, «Los inicios de la revolución industrial en España: la fábrica de algodón de Sevilla (1833-1836)», en Revista del Ministerio de Trabajo y de Asuntos Sociales, 46 (2003), pp. 185-222.

González Huebra, Pablo, Curso de Derecho Mercantil, Madrid, Librería de Sanchez, 1867.

González Sánchez, Carlos Alberto, La Real Compañía de Comercio y Fábricas de San Fernando de Sevilla (1747-1787), Sevilla, Biblioteca de Temas Sevillanos-Ayuntamiento de Sevilla, 1994.

Heredia Herrera, Antonia, Sevilla y los hombres de comercio, Sevilla, Editoriales Reunidas Andaluza, 1989.

«Los modelos andaluces de las ordenanzas de los consulados de comercio borbónicos», en Actas de las VII Jornadas de Andalucía y América, La Rábida, Universidad Internacional de Andalucía, 1987.

«El consulado nuevo de Sevilla y América», en Actas de las Vjornadas de Andalucía y América, La Rábida, Universidad Internacional de Andalucía, 1985.

Hierro Añibarro, Santiago, «El asiento de avería y el origen de la compañía privilegiada en España», en Revista de Historia Económica, vol. 23, 2005, pp. 181-211.

Jiménez Sánchez, Guillermo y Lasarte Álvarez, Javier, La acción en las Compañias privilegiadas (siglo XVIII), Sevilla, Universidad de Sevilla, 1963.

Lobato Chamorro, «Modelos y métodos de gestión de la compañía mercantil preindustrial», en Cuadernos de Estudios Empresariales, 6 (1996), pp. 229-242.

Mariluz Urquijo, José María, Bilbao y Buenos Aíres. Proyectos dieciochescos de compañías de comercio, Buenos Aíres, Universidad de Buenos Aíres, 1981.

Martí de Eixalá, Ramón, Instituciones de Derecho Mercantil de España, Barcelona, 1879, Librería de Álvaro Verdaguer Ramble.

Martínez Gijón, José, Historia del derecho mercantil, Sevilla, Universidad de Sevilla, 1999.

Méndez y Balcarce, Luis, Instituciones y doctrinas de Comercio, Buenos Aires, Instituto de investigaciones de historia del Derecho, 2000. 
Miquel Rubert, Ignacio y Reus García, José, Código de Comercio, Concordado y Anotado, Madrid, Imprenta de Anselmo Santa Coloma, 1855.

Morales Muñoz, Manuel, «El papel de las élites en la industrialización andaluza», en Baetica. Estudios de Arte, Geografía e Historia, 21 (1999), pp. 431-449.

Moreno Alonso, Manuel, «Sobre la vida privada de una familia de comerciantes de Huelva con las Indias», en Fernando Navarro Antolín (coord.), Orbis incognitus: avisos y legajos del Nuevo Mundo: homenaje al profesor Luis Navarro, Vol. 2, (2007), pp. 59-65.

Moscati, Laura, «Dopo e al di lá del Code de commerce: l'apporto di Jean-Marie Pardessus», en Negozianti y imprenditori, 200 anni dal Code de commerce, Milán, Mondadori-Sapienza Universitá di Roma, 2008, pp. 47-80.

«Pardessus e Il Code de Commerce», en Le matrici del diritto commerciale tra storia e tendenze, a cura di Serenella Rossi y Claudia Storti, Bari, Insubria Universtity Press, 2009.

Pardessus, Jean Marie, Cours de droit commercial, tomo II, sexta edición, Augmentée de la Législation et de la Jurisprudence Belges, Bruxelles, Librairie de Jurisprudence de H. Tarliere, 1836.

Petit, Carlos, Historia del derecho mercantil, Marcial Pons, Madrid, 2016.

«El código de comercio de Sainz de Andino: Algunos antecedentes y bastantes críticas», en Revista de Derecho Mercantil, 289 (2013), pp. 109-151.

La compañia mercantil bajo las ordenanzas del Consulado de Bilbao 1737-1829, Sevilla, Universidad de Sevilla, 1980.

Petronio, Ugo «Un diritto nuovo con materiale antichi: il Code de commerce fra tradizione e innovazione», en Negozianti y imprenditori, 200 anni dal Code de commerce, Milán, Mondadori-Sapienza Universitá di Roma, 2008, pp. 1-45.

Recio Mir, Álvaro, «Arquitectura y sociedad: haciendas y hacendados en la Sevilla del siglo XVIII», en Ana María Aranda Bernal (coord.) Arquitectura vernácula en el mundo ibérico: actas del Congreso Internacional sobre arquitectura vernácula, 2007, pp. 78-85.

Rubio, Jesús, Sainz de Andino y la Codificación Mercantil, Madrid, Consejo Superior de Investigaciones Científicas, 1950.

Spada, Paolo, «Il Code de Commerce de 1807 e le costituzione económica», en Le matrici del diritto commerciale tra storia e tendenze, a cura di Serenella Rossi y Claudia Storti, Bari, Insubria Universtity Press, 2009, pp. 33-39.

«Boutiquiers y Padri Costituenti», en Negozianti y imprenditori, 200 anni dal Code de commerce, Milán, Mondadori-Sapienza Universitá di Roma, 2008, pp. 117-140.

Tapia, Eugenio, Elementos de jurisprudencia mercantil, considerablemente aumentada, y refundida con arreglo al nuevo Código de Comercio de 1829, Valencia, Librería de D. Ildefonso Mompié de Montagudo, 1838.

Troplong, Raymond-Théodore, Le droit expliqué du contrat de société civile et commerciale, Paris, Charles Hingray, 1843.

Vicente y Caravantes, José, Código de Comercio, Madrid, Imprenta de D. S. Omaña, 1850. 